\title{
Myeloperoxidase-Oxidized LDLs Enhance an Anti-Inflammatory M2 and Antioxidant Phenotype in Murine Macrophages
}

\author{
Valérie Pireaux, ${ }^{1}$ Aude Sauvage, ${ }^{1}$ Benoît Bihin, ${ }^{2}$ \\ Martine Van Steenbrugge, ${ }^{1}$ Alexandre Rousseau, ${ }^{3}$ Pierre Van Antwerpen, ${ }^{4}$ \\ Karim Zouaoui Boudjeltia, ${ }^{3}$ and Martine Raes ${ }^{1}$ \\ ${ }^{1}$ URBC-Narilis, University of Namur, 61 rue de Bruxelles, 5000 Namur, Belgium \\ ${ }^{2} U M B D$, University of Namur, 61 rue de Bruxelles, 5000 Namur, Belgium \\ ${ }^{3}$ Laboratory of Experimental Medicine (ULB 222 Unit), Université Libre de Bruxelles, CHU-Charleroi, \\ ISPPC Hôpital Vésale, Montigny-Le-Tilleul, Belgium \\ ${ }^{4}$ Therapeutic Chemistry, ULB (Campus de la Plaine) CP205/05, boulevard du Triomphe, Brussels, Belgium
}

Correspondence should be addressed to Valérie Pireaux; valerie.pireaux@unamur.be

Received 25 April 2016; Revised 28 July 2016; Accepted 2 August 2016

Academic Editor: Michal A. Rahat

Copyright (c) 2016 Valérie Pireaux et al. This is an open access article distributed under the Creative Commons Attribution License, which permits unrestricted use, distribution, and reproduction in any medium, provided the original work is properly cited.

\begin{abstract}
Macrophages and oxidized LDLs play a key role in atherogenesis but their heterogeneity has been neglected up to now. Macrophages are prone to polarization and subsets of polarized macrophages have been described in atheromas. LDLs can be oxidized not only chemically by copper (Ox-LDLs) but also enzymatically by myeloperoxidase (MpOx-LDLs) resulting in oxidized LDLs poor in lipid peroxides. The effects of physiologically relevant myeloperoxidase-oxidized LDLs on macrophage polarization or on polarized macrophages remain largely unknown. In this study, the effects of LDLs on macrophage polarization were investigated by monitoring the expression of M1 and M2 genes following stimulation with native LDLs, Ox-LDLs, or MpOx-LDLs in RAW 264.7 cells. Except for MRC1, which is induced only by Ox-LDLs, MpOx-LDLs induced an overexpression of most of the selected marker genes at the mRNA level. MpOx-LDLs also modulate marker gene expression in polarized macrophages favoring notably anti-inflammatory Arg1 expression in M2 cells and also in the other phenotypes. Noteworthy, MpOx-LDLs were the most efficient to accumulate lipids intracellularly in (un)polarized macrophages whatever the phenotype. These data were largely confirmed in murine bone marrow-derived macrophages. Our data suggest that MpOx-LDLs were the most efficient to accumulate within cells and to enhance an anti-inflammatory and antioxidant phenotype in M2 cells and also in the other macrophage phenotypes.
\end{abstract}

\section{Introduction}

Cardiovascular diseases, the major cause of deaths in western societies and throughout the world, are mainly due to atherosclerosis, a chronic inflammatory disease affecting mainly medium and large arteries (WHO, fact sheets of 2016). Local blood flow perturbations or injuries lead to an increased permeability of the endothelial layer, favoring lipoprotein infiltration in the intima, where they get oxidized [1-4]. The oxidized lipoproteins are atherogenic. They activate endothelial cells increasing their chemokine (e.g., MCP-1) and cytokine (e.g., IL-6) secretion, leading to the recruitment of monocytes, which will differentiate into macrophages within the intima [3, 5-7]. However, most of the studies have focused on copper-oxidized LDLs (Ox-LDLs), while more relevant forms of oxidized LDLs have been neglected. Calay and coworkers showed that myeloperoxidase-oxidized LDLs (MpOx-LDLs) activate different signaling cascades in macrophages compared to OxLDLs [8]. Macrophages become foam cells following internalization of these oxidized LDLs through scavenger receptors. Noteworthy, higher intracellular accumulation levels are observed with MpOx-LDLs [8-10].

Macrophages are not homogeneous. Different signals in the cellular environment functionally activate macrophages, modulating their phenotypes as an adaptive response. Classically activated M1 or proinflammatory macrophages are mainly involved in acute host defense owing to their 
microbicidal activity. Exerting cytotoxic and antiproliferative activities by the production of ROS (reactive oxygen species), RNS (reactive nitrogen species), and proinflammatory cytokines (e.g., Interleukin-6), they contribute to tissue destruction and tumor resistance [11-13]. This phenotype can be induced in vitro by interferon- $\gamma$ (IFN- $\gamma$ ) and/or by bacterial stimuli (e.g., LPS), and, over the last years, the combination of LPS and IFN- $\gamma$ has become the standard for inducing "classically" polarized M1 cells in both murine and human macrophages from different sources [11, 1419]. On the contrary, anti-inflammatory M2 macrophages resolve inflammation by the production of anti-inflammatory mediators $[7,12]$. They not only are involved in matrix remodelling, angiogenesis, and tissue repair but also contribute to tumor promotion $[12,13,20]$. These alternatively activated M2 macrophages can be induced in vitro by Interleukin-4 (IL-4) and Interleukin-13 (IL-13) [18].

Another more recently described phenotype (MOX) is induced in vitro by oxidized phospholipids and characterized by high levels of expression of genes regulated by $\mathrm{Nrf} 2$ (nuclear factor erythroid 2-related factor 2) (e.g., heme oxygenase-1 and sulfiredoxin-1) [18, 21-23]. Although less documented, this phenotype, relevant in the context of oxidative stress and probably of atherosclerosis, has been described to represent up to $30 \%$ of the macrophages present in advanced atherosclerotic lesions, at least in LDL- $\mathrm{R}^{-/-}$mice [22].

Despite many recent studies focusing on macrophage polarization, in particular in relation with several chronic diseases, the mechanisms as well as the pathophysiological significance of macrophage polarization in atheroma remain unclear.

In this study, we investigated the effect of native or modified LDLs not only on macrophage polarization but also on polarized macrophages and on foam cell formation. We compared in particular the effects of copper-oxidized and myeloperoxidase-oxidized LDLs. To do so, we first validated the use of the RAW 264.7 murine macrophage-like cell line, which is often used to produce foam cells [24, 25], as a robust and reproducible model for studying macrophage polarization into proinflammatory M1 (also named M(LPS + IFN- $\gamma$ ) according to the "Nomenclature and Experimental Guidelines" about macrophage activation and polarization [26]) and anti-inflammatory M2 (also named M(IL-4 + IL13)) macrophages [26].

The results on RAW cells were validated using murine bone marrow-derived macrophages (BMDMs).

\section{Materials and Methods}

2.1. Cells and Cell Treatments. The murine RAW 264.7 macrophage cell line, obtained from the American Type Culture Collection (ATCC, Manassas, VA, USA), was grown in DHG-L1 medium (Dulbecco's modified Eagle's medium + high glucose $\left.(4,5 \mathrm{~g} / \mathrm{L})+\mathrm{NaHCO}_{3}(1,5 \mathrm{~g} / \mathrm{L})\right)$ (SAFC Global, Lenexa, KS, USA) $+10 \%$ HIS (heat-inactivated fetal calf serum) (Gibco-Life Technologies, Carlsbad, CA, USA). Cells were seeded and treated in 6-well plates (750 000 cells/well) (Corning-Costar, Lowell, MA, USA).
RAW 264.7 cells were polarized towards M1 macrophages by adding LPS (10 ng/mL) (from Escherichia coli (serotype 0111:B4), obtained from Sigma-Aldrich (St. Louis, MO, USA)) in the presence of IFN- $\gamma(20 \mathrm{ng} / \mathrm{mL})$ (R\&D Systems, Minneapolis, MN, USA) or towards M2 cells via the addition of IL-4 combined with IL-13 (20 ng/mL both) (R\&D Systems, Minneapolis, MN, USA) for $18 \mathrm{~h}$. After polarization, media were removed. Then unpolarized (M0 macrophages) and polarized macrophages were incubated for $24 \mathrm{~h}$ with RPMI (Ctl) (RPMI-1640 culture medium (glutamine-free) from Lonza, Basel, Switzerland), native LDLs (Nat-LDLs), $\mathrm{CuSO}_{4}{ }^{-}$ oxidized LDLs (Ox-LDLs), or myeloperoxidase-oxidized LDLs (MpOx-LDLs) at $100 \mu \mathrm{g} / \mathrm{mL}$. RAW 264.7 macrophages were also incubated in the presence of IFN- $\gamma$ only $(20 \mathrm{ng} / \mathrm{mL})$ as a control.

BMDMs (bone marrow-derived macrophages) were obtained from femurs and tibias of 6-to-8-week-old C57BL/6 mice. Mice were euthanized by 1-minute exposure to $\mathrm{CO}_{2}$ followed by cervical dislocation. Once the bone marrow was collected by flushing, cells were incubated for 7 days with DMEM (Gibco-Life Technologies, Carlsbad, CA, USA) supplemented with 10\% heat-inactivated lowendotoxin serum (Sigma-Aldrich, St. Louis, MO, USA), 1\% of penicillin/streptomycin (Life Technologies, Carlsbad, CA, USA), and $10 \%$ of $\mathrm{L} 929$ conditioned media. They were cultured in cell culture Petri dishes (Greiner Bioscience, Frickenhausen, Germany) and were seeded at a density of 500000 cells/well in 6-well plates (Greiner Bioscience, Frickenhausen, Germany) for further analyses. Then BMDMs were polarized and/or stimulated with LDLs with the same protocol as for RAW 264.7 (protocol adapted from [27, 28]).

Mice were handled in strict accordance with good animal practice as defined by the Ethics Committee of the University of Namur. This committee approved all the work planned on animals.

Murine L-929 fibroblasts were obtained from the ATCC and incubated for 6 days with DMEM plus $10 \%$ of heatinactivated low-endotoxin serum in order to produce conditioned medium needed to differentiate murine monocytes into macrophages (BMDMs). L929 conditioned medium is a major source of M-CSF, GM-CSF, and other factors, which stimulate the differentiation and growth of bone marrow cells into macrophages [29].

2.2. LDL Preparation and Oxidation. Native LDLs (NatLDLs) were obtained by sequential density gradient ultracentrifugation from plasma of healthy blood donors. They were prepared, oxidized, and characterized as previously described by Calay et al. [8]. The concentration of Nat-LDLs in PBS was adjusted to $1 \mathrm{mg} / \mathrm{mL}$ before incubation with $10 \mu \mathrm{M}$ copper sulfate for 24 hours at $37^{\circ} \mathrm{C}$. Oxidation was stopped by the addition of $25 \mu \mathrm{M}$ butylated hydroxytoluene (SigmaAldrich, St. Louis, MO, USA) and incubation on ice for 1 hour. MpOx-LDLs were generated by mixing $8 \mu \mathrm{L}$ of $\mathrm{HCl}$ $1 \mathrm{M}$ (final concentration: $4 \mu \mathrm{M}$ ) (Merck, Billerica, MA, USA), $50 \mu \mathrm{L}$ of recombinant human MPO (rhMPO) $86 \mathrm{U} / \mathrm{mL}$ (final relative activity: $2.6 \mathrm{U} / \mathrm{mg} \mathrm{LDL}), 1600 \mu \mathrm{g}$ of LDLs diluted in PBS, and $40 \mu \mathrm{L}$ of $50 \mathrm{mM} \mathrm{H}_{2} \mathrm{O}_{2}$ (final concentration: $1 \mathrm{mM}$ ) (Merck, Billerica, MA, USA). The volume was adjusted to 
$2 \mathrm{~mL}$ with PBS containing $1 \mathrm{~g} / \mathrm{L}$ of EDTA (Merck, Billerica, MA, USA) at $\mathrm{pH}$ 6.5. rhMPO was provided by the Laboratory of Experimental Medicine (ULB 222 Unit, CHU-Charleroi, ISPPC Hôpital Vésale, Belgium). The oxidation reaction for the generation of $\mathrm{MpOx}-\mathrm{LDL}$ was carried out at $37^{\circ} \mathrm{C}$ for 5 minutes and stopped by incubation on ice to inhibit the MPO enzymatic activity. Nat-LDLs, Ox-LDLs, and MpOxLDLs were desalted against RPMI-1640 without glutamine (Lonza, Belgium) by using PD-10 desalting columns (GE Healthcare, Little Chalfont, Buckinghamshire, UK). LDLs were sterile-filtered $(0.2 \mu \mathrm{m})$, stored in the dark at $4^{\circ} \mathrm{C}$, and used within 4 days in order to prevent further oxidation. The LDL concentration was determined by the Lowry method and LDLs were used at a final concentration of $100 \mu \mathrm{g} / \mathrm{mL}$.

\subsection{RNA Extraction and Quantitative Real-Time RT-PCR.} Total RNA, from M0, M1, and M2 macrophages, was extracted according to the manufacturer's protocol using RNeasy Mini Kit (RAW 264.7) or RNeasy Micro Kit (BMDMs) (Qiagen, Hilden, GE). cDNA was synthetized from $2 \mu \mathrm{g}$ of total RNA using the Transcriptor First Strand cDNA Synthesis Kit and according to the manufacturer's instructions (Roche Applied Science, Basel, Switzerland). Forward and reverse primers for TBP, HO-1, Srxn1, Arg1, MRC1, Mgl2, YM1, iNOS, IL-6, Arg2, and TNF- $\alpha$ (Integrated DNA Technologies (IDT) (Coralville, IA, USA)) were designed using the Primer Express 1.5 software (Applied Biosystems, Carlsbad, CA, USA). Real-time RT-qPCR was performed using FastStart Universal SYBR Green Master (Rox) (Roche Applied Science, Basel, Switzerland). The amplification process starts with a denaturation step at $95^{\circ} \mathrm{C}$ for 5 minutes, followed by 40 cycles of denaturation at $95^{\circ} \mathrm{C}$ for 15 seconds and then annealing and extension at $65^{\circ} \mathrm{C}$ for 1 minute, using the 7900 HT Fast Real-Time PCR System (Applied Biosystems, Carlsbad, CA, USA). The gene encoding the Tata-Box Protein (TBP) was selected as a housekeeping gene to normalize data.

2.4. Flow Cytometry. M0, M1, and M2 macrophages were detached with EDTA (Merck, Billerica, MA, USA) (15 minutes at RT) and washed with PBS. After washing, cells were stained with anti-Fc monoclonal antibody (dilution 200x) (BD Pharmingen, Franklin Lakes, NJ, USA) for 20 minutes at $4^{\circ} \mathrm{C}$ and then incubated with primary anti-MRC1 monoclonal antibody (dilution 10x) (Abcam, Cambridge, UK) and secondary anti-IgG-Alexa-488 antibody (dilution 100x) (Invitrogen Molecular Probes, Carlsbad, CA, USA) both for 60 minutes at $4^{\circ} \mathrm{C}$. Finally, they were fixed with PFA 2\% (Sigma-Aldrich, St. Louis, MO, USA) for 20 minutes at $4^{\circ} \mathrm{C}$. Cells incubated with only the primary or secondary antibodies were used as negative controls.

2.5. Western Blotting. After removing the medium, cells were washed in PBS, scraped, and lysed in $30 \mu \mathrm{L}$ of lysis buffer (10 mM Tris (Merck, Billerica, MA, USA), $100 \mathrm{mM}$ $\mathrm{NaCl}$ (Merck, Billerica, MA, USA), 10\% glycerol (Merck, Billerica, MA, USA), 1\% Nonidet P-40 Substitute (SigmaAldrich, St. Louis, MO, USA), 0,1\% sodium dodecyl sulfate
(MP Biochemicals, Solon, OH, USA), 0,5\% sodium deoxycholate (Merck, Billerica, MA, USA)) containing a proteinase inhibitor "Complete" cocktail (Roche Molecular Biochemicals, Basel, Switzerland) and phosphatase inhibitors (25 mM $\mathrm{Na}_{3} \mathrm{VO}_{4}, 250 \mathrm{mM}$ 4-nitrophenyl phosphate (Sigma-Aldrich, St. Louis, MO, USA), $250 \mathrm{mM} \beta$-glycerophosphate (VWR, Radnor, PA, USA), and $125 \mathrm{mM} \mathrm{NaF}$ (Merck, Billerica, MA, USA) at a $1 / 25$ dilution in $\mathrm{H}_{2} \mathrm{O}$ ) for 30 minutes at $4^{\circ} \mathrm{C}$. Lysates were then centrifuged at $15700 \mathrm{rcf}$ for 10 minutes (Eppendorf Microcentrifuge 5415R). Protein concentration was determined using the Pierce 660 protein assay and $15 \mu \mathrm{g}$ (RAW 264.7 cells) or $5 \mu \mathrm{g}$ (BMDMs) of proteins was loaded on 420\% SDS-PAGE gels (Bio-Rad Laboratories, Hercules, CA, USA). Proteins were transferred onto a polyvinylidene fluoride (PVDF) membrane $(0,45 \mu \mathrm{m})$ (Millipore, Billerica, MA, USA) for 2 hours at $70 \mathrm{~V}$. Primary antibodies are mouse antiHO-1 (heme oxygenase-1) monoclonal antibody (Thermo Scientific, Waltham, MA, USA), rabbit anti-sulfiredoxin polyclonal antibody (Proteintech, Chicago, IL, USA), and rabbit anti-TBP polyclonal antibody (Santa Cruz Biotechnology, Dallas, TX, USA) (dilution 1000x). Secondary antibodies are either IRDye $800 \mathrm{CW}$ goat anti-mouse antibodies or IRDye 680 goat anti-rabbit antibodies (LI-COR, Lincoln, NE, USA) (dilution 10000x). Quantitative analysis of fluorescence intensity was performed using the Odyssey Classic Infrared Imaging System (LI-COR, Lincoln, NE, USA).

2.6. ELISA Assay. Supernatants were harvested. They were then centrifuged at $15700 \mathrm{rcf}$ at $4^{\circ} \mathrm{C}$ and pellets were discarded. Mouse IL-6, IL-12, TNF- $\alpha$, and IL-10 ELISA assays were performed following manufacturer's instructions (R\&D Systems, Minneapolis, MN, USA).

2.7. Analysis of the Number and Size of Lipid Droplets. Cells seeded in 96-well plates were fixed with PFA 4\% for $10 \mathrm{~min}$ utes at RT. After washing with PBS, they were permeabilized with PBS-Triton $1 \%$ for 5 minutes at RT, washed with PBSBSA 2\%, and incubated with BODIPY 493/503 (dilution: 1/40) (Invitrogen Molecular Probes, Carlsbad, CA, USA) for 2 hours in the dark at RT. They were finally incubated with Phalloidin-Alexa 555 (dilution: 1/50) (Invitrogen Molecular Probes, Carlsbad, CA, USA) and Hoechst FluoroPure grade (dilution: 1/1000) (Invitrogen Molecular Probes, Carlsbad, CA, USA) for 30 minutes in the dark at RT and analyzed using the BD Pathway 855, with the AttoVision software and BDIDE software (lens: 20x) (Becton Dickinson, Franklin Lakes, NJ, USA).

2.8. Cholesterol Quantitation. Cells were seeded in 6-well plates at a density of $1 \cdot 10^{6}$ cells/well, polarized for 18 hours, and incubated or not with LDLs for 24 hours. After this incubation, cholesterol was extracted from cells by adding $200 \mu \mathrm{L}$ of chloroform : isopropanol: IGEPAL CA-630 (7:11:0.1) in a microhomogenizer. The solution was then centrifuged at $13000 \times \mathrm{g}$ for 10 minutes in order to remove insoluble material. The organic phase was transferred in a new tube, airdried at $50^{\circ} \mathrm{C}$ to remove chloroform, and put under vacuum for 30 minutes to remove any residual organic solvent. The 
dried lipids were dissolved with $220 \mu \mathrm{L}$ of the cholesterol assay buffer and were vortexed until the lipid solution was homogeneous. Cholesterol was finally quantified following the manufacturer's instructions by using reaction mixes containing the cholesterol assay buffer, probe, enzyme mix, and/or cholesterol esterase. The absorbance was measured at $570 \mathrm{~nm}$ (Cholesterol Quantitation Kit MAK043) (SigmaAldrich, St. Louis, MO, USA) and results were expressed as $\mu \mathrm{g} / \mu \mathrm{L}$ of free, esterified, or total cholesterol following the manufacturer's instructions.

2.9. Phagocytosis Assay. Cells were seeded in 12 -well plates at a density of $5 \cdot 10^{5}$ cells/well and were polarized for 18 hours. They were then incubated or not with LDLs $(100 \mu \mathrm{g} / \mathrm{mL})$ and fluorescent beads (dilution: 1/133) for 24 hours. Phagocytosis of fluorescent beads was measured by flow cytometry, using the FACS BD Verse (Becton Dickinson, Franklin Lakes, NJ, USA). The phagocytosis assay of fluorescent beads was performed following manufacturer's instructions (Phagocytosis Assay Kit (IgG FITC) Item number 500290) (Cayman Chemical, Ann Arbor, MI, USA).

2.10. Statistical Analysis. R (version 3.0.3; the R Foundation for Statistical Computing) was used for statistical analysis. As RT-qPCR data presents highly heterogeneous variances, statistical analyses were performed on log-transformed data and, in order to facilitate interpretation, untransformed data are shown (Figures 4(a), 4(b2), 5, and 7(b), and S1C, and S1D in Supplementary Material available online at http://dx.doi.org/10.1155/2016/8249476).

Before measuring the mean comparisons, homoscedasticity was assessed with Bartlett's test.

When homoscedasticity could be assumed ( $p$ value $>$ 0.05), we performed one-way (Figures 1, 2, 3, 6, 7(a), S1A, $\mathrm{S} 1 \mathrm{~B}, \mathrm{~S} 2 \mathrm{~A}, \mathrm{~S} 3 \mathrm{~A}$, and S4) or two-way ANOVA according to the experimental design. Post hoc pairwise mean comparisons were then performed with Tukey's method. Following twoway ANOVA, pairwise comparisons were performed among marginal means if there was no statistically significant interaction and among cell means otherwise (Figures 4(a) and S5: except MRC1, Figures 4(b) and 5(a): Arg1 and IL-6, and Figures 5(b) and S6).

When homoscedasticity could not be assumed ( $p$ value $<$ 0.05), we performed Kruskal-Wallis rank-sum test followed by pairwise comparisons on main effects using Wilcoxon rank-sum test (Figures 4(a) and S5: MRC1, Figure 5(a): except for Arg1 and $I L-6$, and Figures 7(b), S1C, S1D, S2B, and S3B).

Data were expressed as mean \pm standard error of the mean.

\section{Results}

3.1. RAW 264.7 Macrophages Can Be Polarized into M1 and M2 Macrophages. Unpolarized RAW 264.7 macrophages (M0) were polarized into M1 and M2 macrophages using LPS and IFN- $\gamma$ for the M1 phenotype and IL- 4 and IL-13 for the M2 phenotype $[14,19,22]$. We confirmed the respective phenotypes by measuring the expression of marker genes
[30-33] both at the mRNA level and at the protein level (Figures 1, S1A, S2A, and S3A (see Supplementary materials)). At the mRNA level, M1 macrophages overexpressed proinflammatory genes, such as inducible Nitric Oxide Synthase and Interleukin-6 (Figure 1(a)) as well as Arg2 and TNF$\alpha$ (Figure S2A), while M0 and M2 macrophages did not. Contrary to M0 and M1 macrophages, M2 macrophages overexpressed anti-inflammatory genes, such as arginase1 and mannose receptor-C1 (MRC1) (Figure 1(a)) as well as $\mathrm{Mgl} 2$ (macrophage galactose $\mathrm{N}$-acetyl-galactosamine specific lectin 2) and YM1 (beta-N-acetylhexosaminidase, also known as Chil3, chitinase-like protein 3) (Figure S1A). In M1 cells, we also observed an overexpression of heme oxygenase1 (HO-1) and sulfiredoxin-1 (Srxn1). The latter are driven by $N r f 2$ and considered as markers of oxidative stress as well as of the so-called MOX macrophages, a less documented phenotype [22] (Figure 1(a)). Increased expression of some marker genes was confirmed at the protein level, respectively, by ELISA, for secreted IL-6 (Figure 1(b1)), and by flow cytometry analysis, for MRC1 (Figure 1(b2)). We also checked, by ELISA, the expression of IL-10, generally considered as an anti-inflammatory cytokine (M2 marker), which was higher in M2 macrophages, and the expression of both proinflammatory cytokines IL-12 and TNF- $\alpha$ (M1 markers), which was higher in M1 macrophages (Figure $\mathrm{S} 3 \mathrm{~A}$ ). Western blot analysis confirmed that $\mathrm{HO}-1$ abundance was higher in M1 macrophages, while no clear difference in abundance was observed for Srxn1 (Figure 1(b3)). IFN- $\gamma$ alone induced to some extent the secretion of TNF- $\alpha$ but was unable to polarize the cells into M1 cells (data not shown).

The same protocols of polarization were applied to bone marrow-derived macrophages (BMDMs) obtained from the differentiation of bone marrow cells collected from femurs and tibias of 6-to-8-week-old C57BL/6 mice (Figures 2 and $\mathrm{S} 1 \mathrm{~B})$. We observed the same trend when considering the expression of M1 and M2 markers (especially arginase-1, $\mathrm{Mgl2}$, and YM1) in M1 and M2 macrophages, respectively (Figures 2(a) and S1B). The redox-sensitive genes, HO-1 and Srxn1, were also overexpressed in M1 macrophages.

In summary, these results show that the RAW 264.7 cells can easily be polarized into M1 or M2 macrophages, displaying marker gene expression patterns consistent with those observed in polarized BMDMs. Fold inductions are generally higher in BMDMs and especially in M1 BMDMs (Figure 2(a)).

\subsection{Myeloperoxidase-Oxidized LDLs Are the Most Efficient} in Modulating Polarization Gene Marker Expression. Using the validated RAW 264.7 macrophage model, we evaluated the potential of LDLs to polarize macrophages. Unpolarized macrophages were stimulated with native LDLs (Nat-LDLs), copper sulfate-oxidized LDLs (Ox-LDLs), and myeloperoxidase-oxidized LDLs (MpOx-LDLs) and the expression of M1 and M2 marker genes was determined at the mRNA (Figure 3(a)) and protein levels (Figures 3(b)). While copper sulfate oxidation alters both the protein and lipid moieties, myeloperoxidase oxidizes mainly Apo-B100, generating low levels of lipid hydroperoxides [34-36]. 



(a)

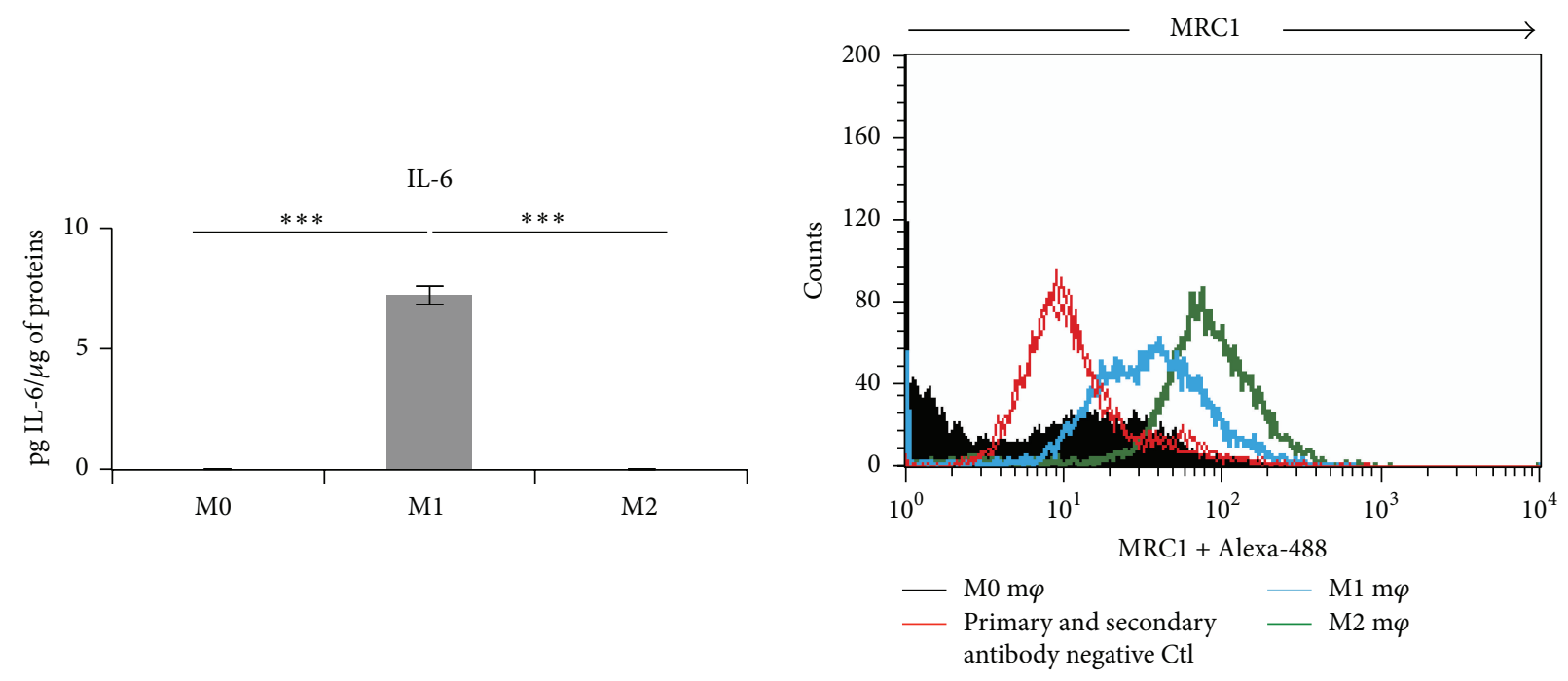

(b1)

FIGURe 1: Continued. 

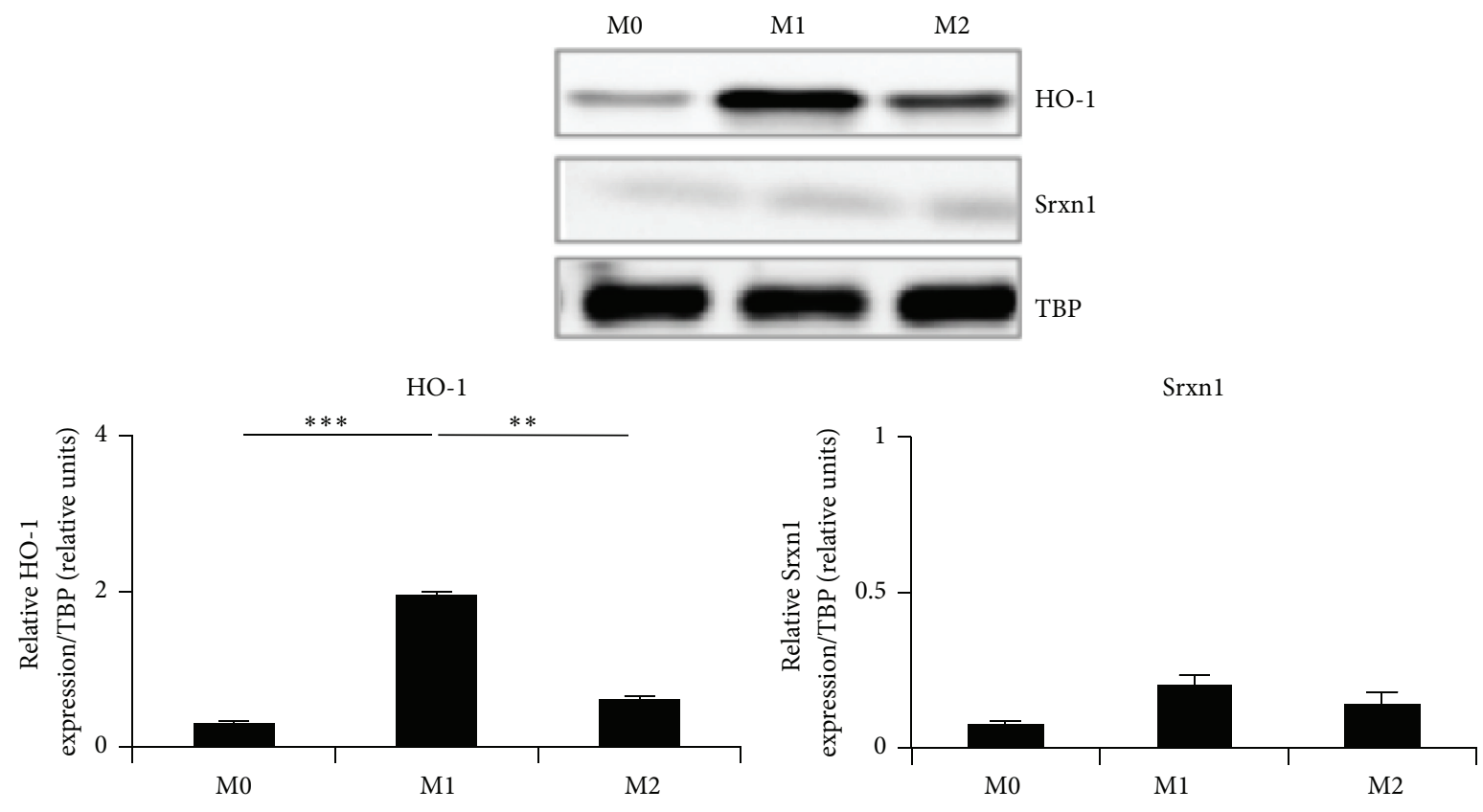

(b3)

(b)

Figure 1: Characterization of RAW 264.7 M0, M1 (LPS + IFN- $\gamma$ ), and M2 (IL-4 + IL-13) polarized macrophages. Cells were polarized as described in Materials and Methods. (a) Expression of polarization marker genes at the mRNA level (RT-qPCR), in M0, M1, and M2 macrophages. The expression of $i N O S$ and IL-6 as M1 markers, Argl and MRC1 as M2 markers, and HO- 1 and Srxn1 as MOX redox-sensitive markers was analyzed by RT-qPCR. Data were normalized with TBP used as housekeeping gene and expressed as mean fold induction relatively to M0 cells \pm SD $(n=3)$. (b) Expression of polarization markers at the protein level in M0, M1, and M2 macrophages. (b1) Production of secreted IL-6 (M1 marker) in cell culture supernatants assessed by ELISA. Data are expressed relatively per $\mu \mathrm{g}$ of protein per well as mean $\pm \mathrm{SD}(n=3)$. (b2) Surface expression of MRC1 (M2 marker) analyzed by flow cytometry in M0, M1, and M2 macrophages (m $\varphi)$. GMF (geometric mean of the fluorescence intensity) values are reported in arbitrary units: $\Delta \mathrm{GMF}_{\mathrm{M} 2-\mathrm{M} 0}, 65.57$ and $\Delta \mathrm{GMF}_{\mathrm{M} 1-\mathrm{M} 0}, 28.9$. The data presented are representative of 3 independent experiments. (b3) Expression of HO-1 and Srxnl assessed by Western blotting in M0, M1, and M2 macrophages. Data are normalized with TBP used as loading control and expressed as mean \pm SD $(n=3)$. Results are representative of 3 independent experiments. ANOVA $1:{ }^{* *} p<0.01$ and ${ }^{* * *} p<0.001$.

First, we assessed the mRNA abundance of the selected marker genes and observed that native LDLs have no marked effect on macrophage polarization. Ox-LDLs mainly induced an increased expression of MRC1, a M2 marker gene $(p<$ 0.001) [32]. MpOx-LDLs were the most potent to induce the expression of all the selected marker genes (iNOS, Arg1, and MRC1: $p<0.05$; IL-6, HO-1, and Srxn1: $p<0.001)$ (Figure 3(a)).

While the M1 markers iNOS and IL-6 and the M2 marker Arg1 were only induced following MpOx-LDLs treatment, both Ox-LDLs- and MpOx-LDLs-treated cells overexpressed the M2 marker MRC1 (Figure 3(a)). However, the fold induction at the mRNA level for iNOS, Argl, and MRC1 remained significantly lower compared to polarized M1 and M2 macrophages (Figures 1(a) and 3(a)). At the protein level (Figure 3(b2)), MRC1 abundance was higher in the presence of both Ox-LDLs and MpOx-LDLs, but in the presence of MpOx-LDLs a majority of cells clearly expressed higher levels of MRC1, compared to Ox-LDLs-treated cells. The effect of LDLs was also tested on the secretion of various cytokines. In contrast to the mRNA data, IL-6 abundance was higher in the presence of Ox-LDLs $(p<0.001)$ (Figure 3(b1)), while no significant effect was observed for IL-10, IL-12, and TNF$\alpha$ whatever the LDLs used as compared to Ctl cells (Figure S4). HO-1 and Srxn1 expressions increased at the protein level in unpolarized cells treated with both Ox-LDLs (HO-1: $p<0.01)$ and MpOx-LDLs (HO-1 and Srxnl: $p<0.001)$ but more effectively with the latter (Figure 3(b3)). Overall, these data suggest that MpOx-LDLs by themselves tend to favor an intermediate phenotype slightly inducing the expression of some M2 markers and antioxidant enzymes.

3.3. Ox-LDLs and MpOx-LDLs Differentially Modulate the Phenotype of Polarized Macrophages. We next investigated the possible influence of LDLs on polarized macrophages. M1 and M2 RAW 264.7 cells (Figures 4, S1C, S2B, S3B, and S5) and BMDMs (Figures 5 and S1D) were stimulated with native LDLs, Ox-LDLs, and MpOx-LDLs. Incubation in RPMI medium devoid of LDLs was also performed and the level of expression of the polarization markers in M0 RPMI incubated cells was used as the reference condition.

First, our data show that, in particular for M1 and M2 cells, marker gene overexpression is maintained compared 



(a)

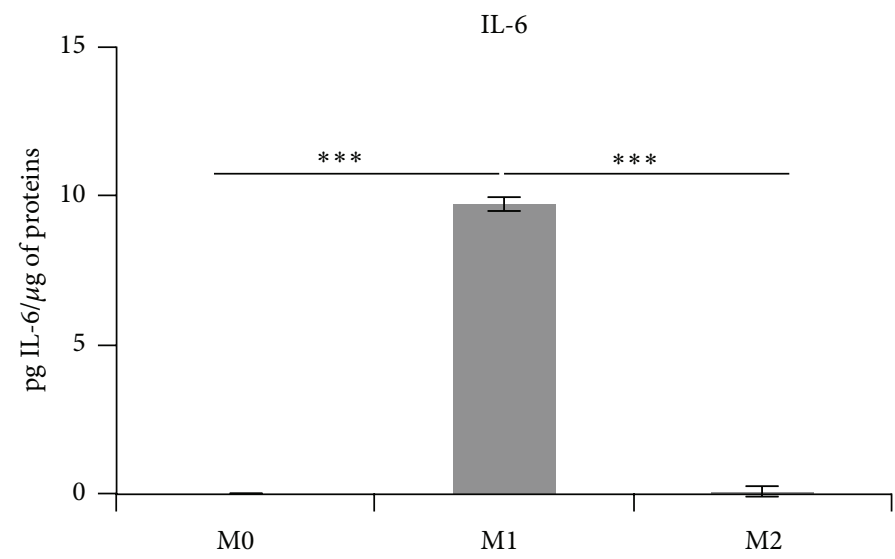

(b1)

FIgure 2: Continued. 

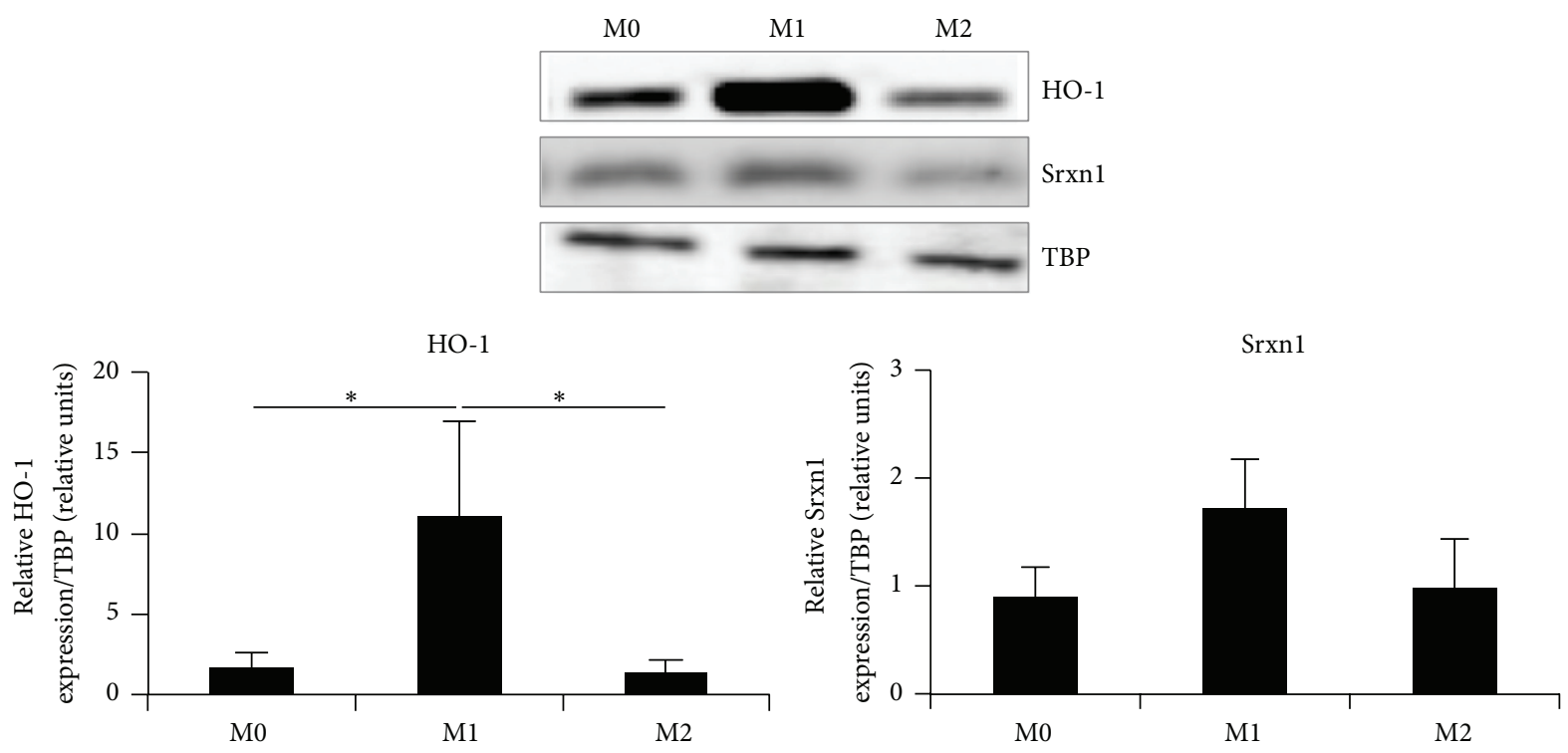

(b2)

(b)

FIGURE 2: Characterization of M0, M1, and M2 polarized BMDMs. (a) Expression of polarization marker genes at the mRNA level (RT-qPCR) in M0, M1, and M2 macrophages. The expression of marker genes was analyzed as described in Figure 1 and the data were expressed as mean fold induction relatively to M0 cells $\pm \mathrm{SD}(n=3)$. (b) Expression of polarization markers at the protein level in M0, M1, and M2 macrophages. (b1) Production of secreted IL-6 (M1 marker) in cell culture supernatants assessed by ELISA. Data are expressed relatively per $\mu \mathrm{g}$ of protein per well as mean \pm SD $(n=3)$. (b2) Expression of HO-1 and Srxn1 assessed by Western blotting in M0, M1, and M2 macrophages. Data are normalized with TBP used as loading control and expressed as mean \pm SD $(n=4)$. Results are representative of 4 independent experiments. ANOVA $1:{ }^{*} p<0.05$ and ${ }^{* * *} p<0.001$.

to M0 cells whatever the treatment. However, LDLs, and in particular MpOx-LDLs, seem to exert some modulatory effects. As there is no interaction between variables, we were able to look at the main effects for M1 and for M2 cells. Regarding the proinflammatory markers, we can conclude that iNOS expression in M1 cells seemed to be affected by MpOx-LDLs, especially in RAW 264.7 cells, but not by OxLDLs (RAW 264.7: MpOx-LDLs versus RPMI $p<0.001$, OxLDLs versus RPMI $p>0.05$; BMDMs: $p>0.05)$, while $I L-6$ mRNA abundance was in general decreased in the presence of LDLs (RAW 264.7: Nat-LDLs versus RPMI $p<0.05$, OxLDLs versus RPMI $p<0.05$, and MpOx-LDLs versus RPMI $p>0.05$; BMDMs: Nat-LDLs versus RPMI $p<0.001$, OxLDLs versus RPMI $p<0.001$, and MpOx-LDLs versus RPMI $p<0.001$ ) (Figures 4(a) and 5(a)), although this difference was not confirmed at the protein level (Figures 4 (b) and 5(b)). Interestingly, we observed the same effects, as for $I L$ 6 , with TNF- $\alpha$ at the mRNA level (Nat-LDLs versus RPMI $p<0.05$, Ox-LDLs versus RPMI $p<0.05$, and MpOx-LDLs versus RPMI $p<0.01$ ) (Figure S2B). The mRNA expression of Arg2 was maintained in M1 macrophages whatever the treatment (native or modified LDLs versus RPMI $p>0.05$ ) (Figure S2B). At the protein level, the abundance of IL-6, IL-12, and TNF- $\alpha$ was maintained in M1 RAW 264.7 cells whatever the treatment $(p>0.05)$ (Figures $4(\mathrm{~b} 1)$ and S3B). As well as for M1 cells, we looked for the main effects on M2 cells. The expression of Arg1, an anti-inflammatory gene and M2 marker, appears to be reinforced both in RAW 264.7
(Figure 4(a)) and in bone marrow-derived (Figure 5(a)) M2 macrophages incubated with MpOx-LDLs $(p<0.001)$ but not in the presence of Ox-LDLs $(p>0.05)$ (Figures 4(a) and 5(a)). When compared to results of Arg1 expression, the effects of MpOx-LDLs on MRC1 expression in M2 cells were similar in BMDMs but were less clear in RAW 264.7 cells $(p>0.05)$. Furthermore, when zooming Figure 4(a) (in Figure S5), we observed that MpOx-LDLs also slightly induced $\operatorname{Arg1}(p<0.001)$ and $M R C 1(p>0.05$, with similar patterns between replicates; except in M0: $p<0.05)$ in M0 and M1 macrophages.

At the protein level (Figure S3B), we also observed that MpOx-LDLs induce an increased secretion of IL-10 in M0 cells (MpOx-LDLs versus RPMI $p<0.01$ ). In M1 cells, there seems to be a similar trend, but the effect is not significant $(p>0.05)$ probably because of the prevalent proinflammatory effect of LPS. Interestingly, in IFN- $\boldsymbol{\gamma}$-treated macrophages, we also observed a significant induction of IL-10 (data not shown), confirming the anti-inflammatory properties of MpOx-LDLs. The expression of IL-10 was maintained in M2 macrophages whatever the treatment $(p>$ $0.05)$. There were no major noticeable effects for IL-12 or TNF- $\alpha$ whatever the treatment.

In bone marrow-derived macrophages, it has to be mentioned that M0 macrophages, possibly due to the presence of M-CSF in the differentiation medium, expressed MRC1 at both the mRNA level (Figure 5(a)) and at protein level (data not shown) $[29,37,38]$. By looking at the main effects for the 

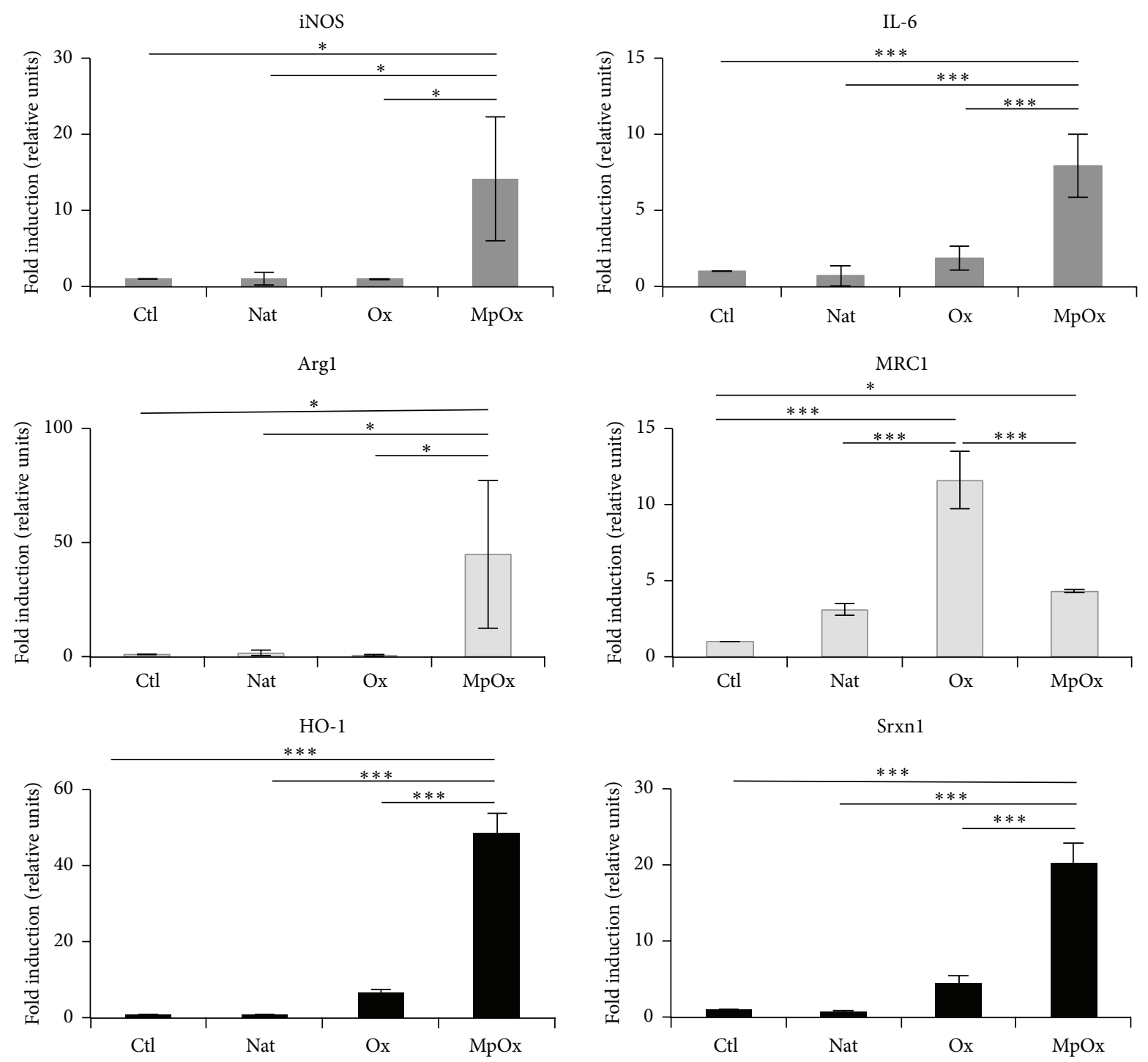

(a)


(b1)

FIGURE 3: Continued. 


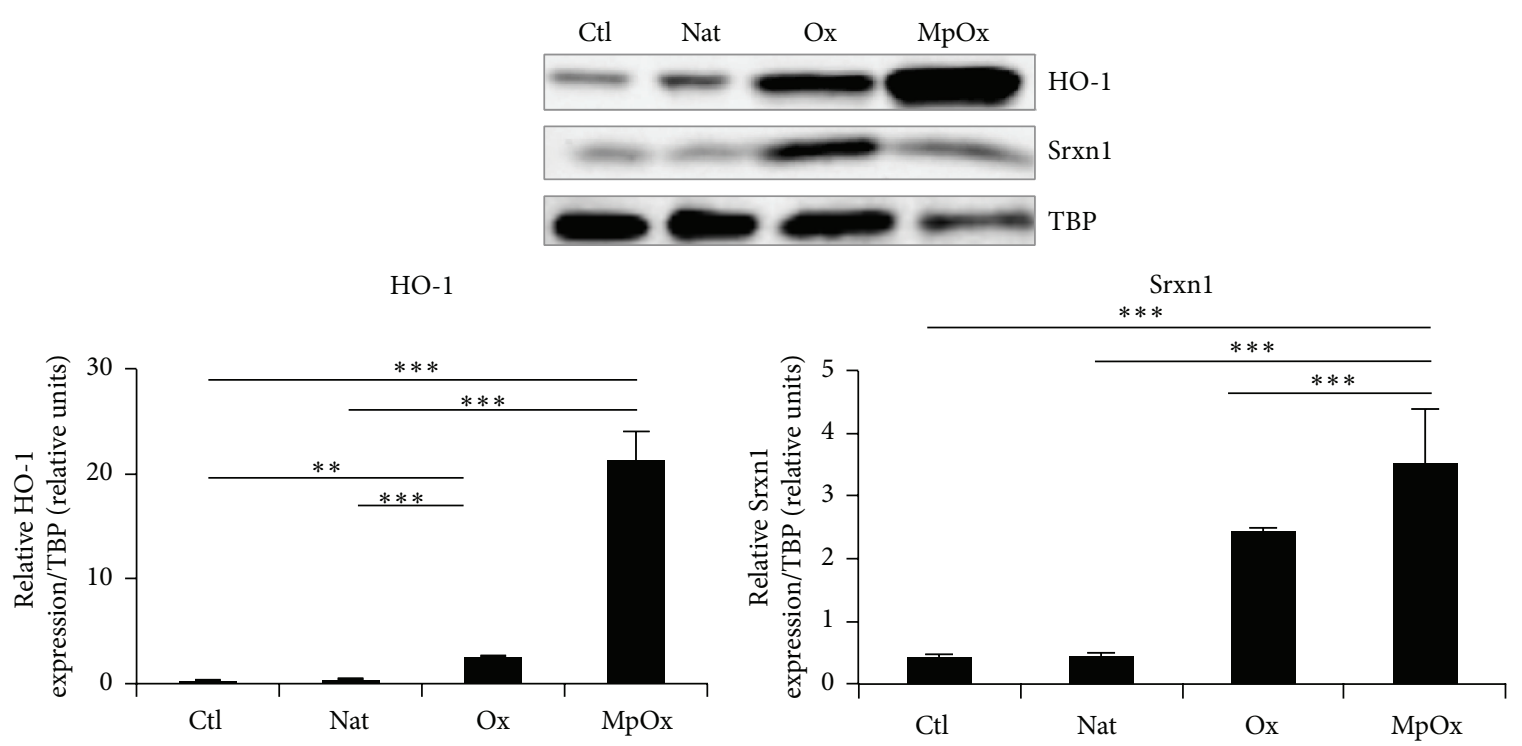

(b3)

(b)

FIGURE 3: Comparative effects of LDLs on marker gene expression in unpolarized RAW 264.7 M0 macrophages. M0 macrophages were treated for 24 hours in the presence of medium alone (Ctl), native LDLs (Nat), Ox-LDLs (Ox), or MpOx-LDLs (MpOx) (100 $\mu \mathrm{g} / \mathrm{mL})$. (a) Expression of polarization marker genes at the mRNA level (RT-qPCR). The expression of marker genes was analyzed by RT-qPCR as in Figure 1. Data are normalized with TBP used as housekeeping gene and expressed as mean fold induction relatively to Ctl cells \pm SD $(n=3)$. (b) Expression of polarization markers at the protein level (FACS, ELISA, and WB) in Ctl and Nat-LDLs-, Ox-LDLs-, and MpOx-LDLstreated M0 macrophages. (b1). Production of secreted IL-6 (M1 marker) in cell culture supernatants assessed by ELISA. Data are expressed relatively per $\mu \mathrm{g}$ of protein per well as mean $\pm \mathrm{SD}(n=3)$. (b2) Surface expression of MRC1 (M2 marker) analyzed by flow cytometry in Ctl and treated macrophages $(\mathrm{m} \varphi)$. GMF values are reported in arbitrary units: $\Delta \mathrm{GMF}_{\mathrm{Nat}-\mathrm{CTL}}, 0 ; \Delta \mathrm{GMF}_{\mathrm{Ox}-\mathrm{CTL}}, 20.75$; and $\Delta \mathrm{GMF}_{\mathrm{MpOx}-\mathrm{CTL}}, 33.82$. The data presented are representative of 3 independent experiments. (b3) Expression of HO-1 and Srxn1 assessed by Western blotting in Ctl and Nat-LDLs-, Ox-LDLs-, and MpOx-LDLs-treated macrophages. Data are normalized with TBP used as loading control and expressed as mean \pm SD $(n=3)$. Results are representative of 3 independent experiments. ANOVA $1:{ }^{*} p<0.05 ;{ }^{* *} p<0.01 ;$ and ${ }^{* * *} p<0.001$.

following conditions because there is no interaction between variables, we can conclude that $M R C 1$ expression is low in M1 cells (RAW 264.7: $p<0.001$; BMDMs: $p<0.001$ ) but is maintained in M2 cells (RAW 264.7: $p<0.001$; BMDMs: $p>0.05)$ with no significant effect of any kind of LDLs (Figure 5(a)).

The expression of two other M2 markers, Mgl2 and YM1, was evaluated in M0, M1, and M2 macrophages incubated with oxidized LDLs or not (Figures S1C and S1D). However, only YM1 expression in RAW 264.7 cells was increased by MpOx-LDLs whatever the phenotype $(p<0.05$ in M1 and M2 cells) (Figure S1C). The effects of MpOx-LDLs on YM1 expression were less clear in BMDMs (Figure S1D).

Regarding the Nrf2 driven genes, so-called MOX gene markers, our data clearly show that they are less specific. Comparing the main effects between the different phenotypes, we can come to the conclusion that M1 cells (RAW 264.7 and BMDMs) clearly strongly overexpress HO-1 (RAW 264.7: $p<$ 0.001; BMDMs: $p<0.001$ ), probably due to the presence of LPS [39-41]. This overexpression is, however, reinforced in the presence of oxidized LDLs (in those conditions, RAW 264.7: $p<0.001$; BMDMs: Ox-LDLs versus RPMI $p>0.05$, MpOx-LDLs versus RPMI $p<0.05)$. It has to be mentioned that we also observe a slight induction of HO-1 in M0 and M2 cells treated with oxidized LDLs, known to activate Nrf2, compared to RPMI medium and native LDLs (in M0 and M2 cells treated either with OxLDLs (RAW 264.7 cells: $p<0.001$; BMDMs: $p>0.05$ (M0), $p<0.05$ (M2)) or with MpOx-LDLs (RAW 264.7: $p<0.001$; BMDMs: $p<0.05)$ ), which was confirmed at the protein level (Figure 4(b2) for RAW 264.7 cells and Figure 5(b2) for BMDMs).

We observed partially the same trend for Srxn1 at least in RAW 264.7 polarized macrophages at the mRNA level $(p<0.01)$ (Figure 4(a)). In (un)polarized BMDMs, the effects of (un)modified LDLs on Srxn1 expression were less clear (Figures 5(a) and 5(b2)).

Finally, we wanted to check to what extent LDLs were able to modulate the phagocytosis potential of (un)polarized macrophages (Figure S6). M1 cells seemed slightly more efficient (nonsignificant) to internalize beads, which is in agreement with their functions. It has to be mentioned that Fc $\gamma$ R3, one of the potential receptors for the IgG coated latex beads, is overexpressed in M1 macrophages, compared to M0 and M2 RAW 264.7 macrophages (data not shown) $[42,43]$. However, we were unable to demonstrate any effect of LDLs on this process whatever the macrophage source or phenotype. A similar trend, although less pronounced, was observed in BMDMs (Figure S6B). 


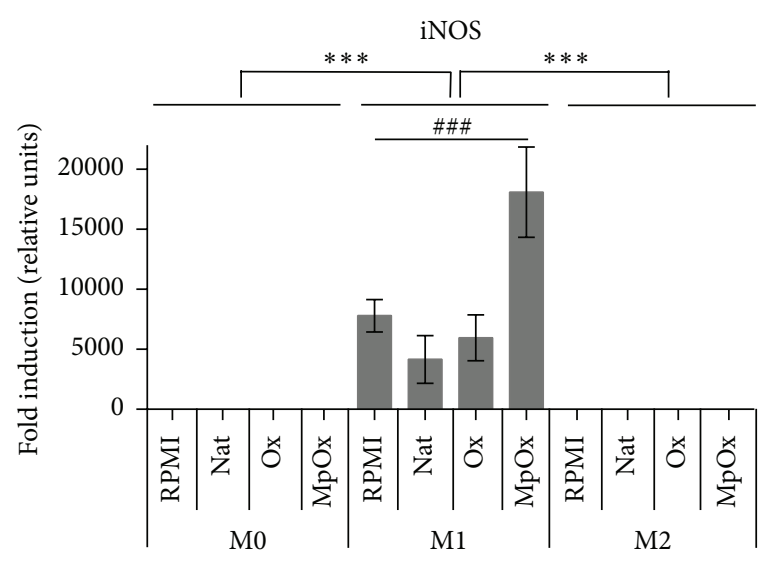

IL-6
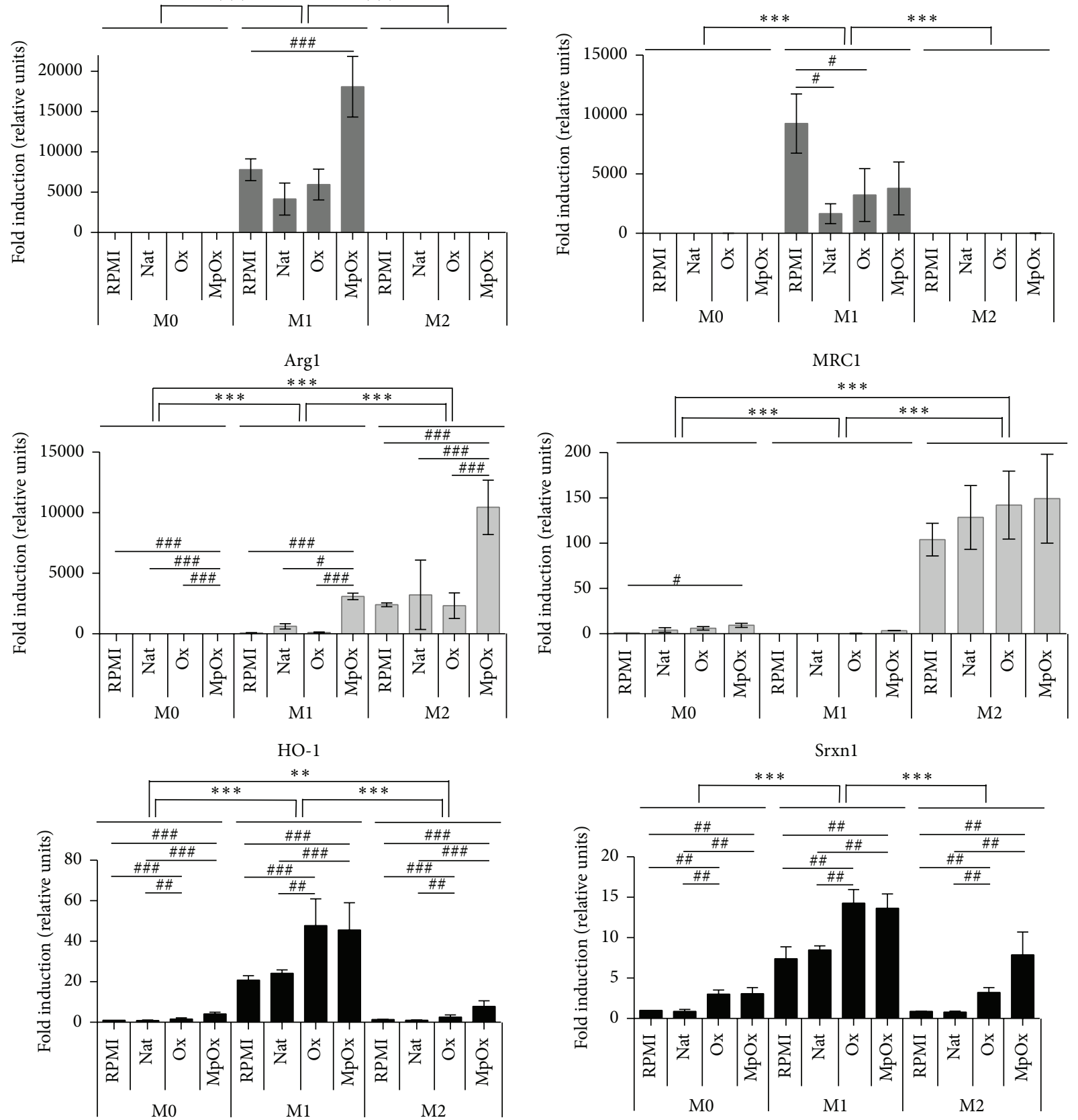

(a)

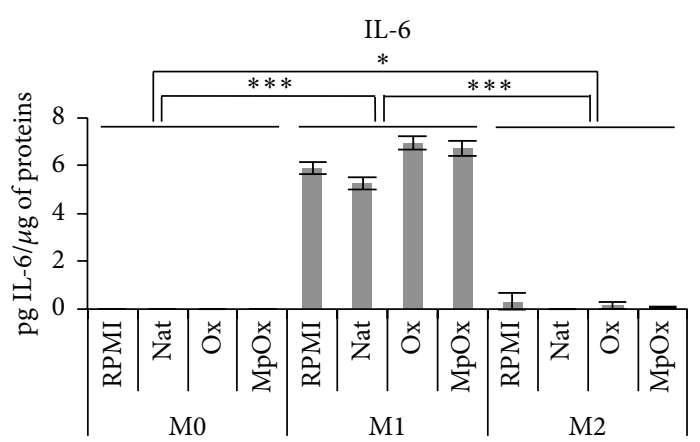

(b1)

FIgUre 4: Continued. 

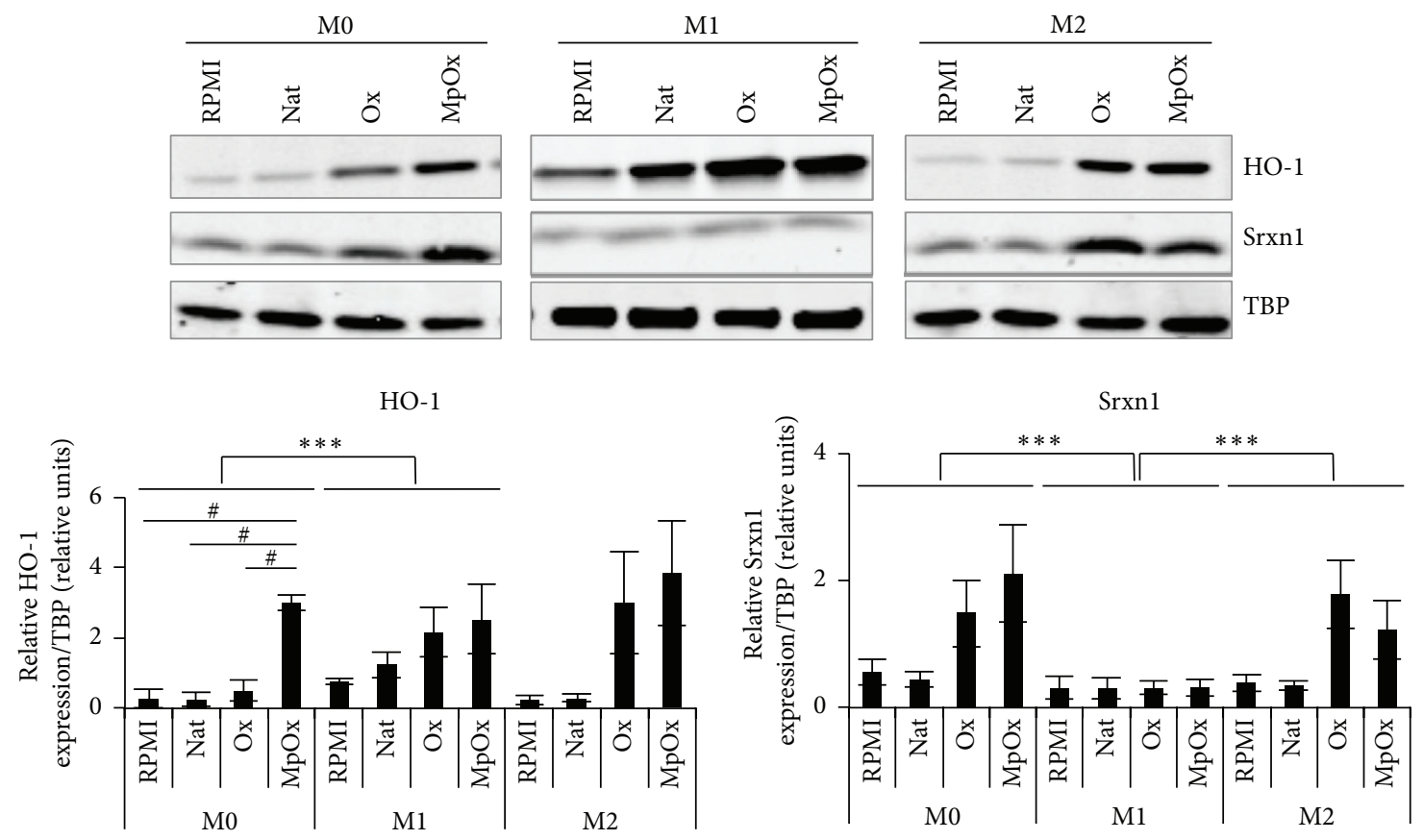

(b2)

(b)

FIGURE 4: Comparative effects of LDLs on (un)polarized RAW 264.7 macrophages. M0, M1, and M2 macrophages were stimulated in the presence or absence (RPMI control) of Nat-LDLs, Ox-LDLs, and MpOx-LDLs for 24 hours $(100 \mu \mathrm{g} / \mathrm{mL})$. (a) Expression of polarization marker genes at the mRNA level (RT-qPCR). The expression of marker genes was analyzed by RT-qPCR as described in Figure 1. Data are normalized with TBP used as housekeeping gene and expressed as mean fold induction relatively to M0 cells in RPMI \pm SD $(n=6)$. Data for MRC1 were analyzed by a Kruskal-Wallis ANOVA on ranks. Zoomed data for Arg1 and $M R C 1$ are presented in Figure S5. (b). Expression of polarization marker genes at the protein level (ELISA; WB). (b1) Production of secreted IL-6 (M1 marker) in cell culture supernatants assessed by ELISA. Data are expressed relatively per $\mu$ g of protein per well as mean \pm SD $(n=3)$. (b2) Expression of HO-1 and Srxn1 assessed by Western blotting. Data are normalized with TBP used as loading control and expressed as mean \pm SD $(n=3)$. Results are representative of 3 independent experiments. ANOVA 2: ${ }^{*, \#} p<0.05 ;^{* *, \# \#} p<0.01$; and ${ }^{* * *, \# \# \#} p<0.001$.

3.4. Comparative Effects of (Un)Modified LDLs on the Differentiation of Polarized Macrophages into Foam Cells. Macrophage differentiation into foam cells was evaluated by measuring the number and the size of these lipid droplets per cell in RAW 264.7 cells (Figure 6) and in BMDMs (Figure 7(a)). MpOx-LDLs were the most efficient to induce lipid accumulation in M0 and M2 macrophages when compared to native LDLs and Ox-LDLs. M1 cells, contrary to the other phenotypes, engulfed not only oxidized but also native LDLs, probably due to their oxidative metabolism. The mean surface areas of lipid droplets within these cells were consistent with the data presented in Figures 6 and 7(a) (data not shown). Similar results were obtained on RAW 264.7 cells (Figure 6) and on BMDMs (Figure 7(a)).

We also evaluated the intracellular cholesterol content. In BMDMs (Figure 7(b)), the intracellular content of cholesterol increased in the presence of oxidized LDLs, which is in agreement with the data on lipid droplets (Figure 7(a)), with MpOx-LDLs being the most efficient to contribute to the increase of intracellular cholesterol.

However, in RAW 264.7 macrophages, no significant differences were observed. This discrepancy could be explained by a high basal content of cholesterol (8-fold compared to
BMDMs). Because of this high basal content, small variations in intracellular cholesterol, after endocytosis, would be difficult to assess due to a lack of sensitivity of the assay (data not shown).

\section{Discussion}

In the present study, we showed that RAW 264.7 macrophages, commonly used as a model in studies related to atherosclerosis and prone to differentiate into foam cells $[8,44-46]$, can be polarized towards M1 and M2 phenotypes. Furthermore, we showed that MpOx-LDLs were the most efficient to interfere with macrophage polarization and enhance an anti-inflammatory and antioxidant phenotype.

Macrophages, and more specifically foam cells, are considered as key players in the initiation and the evolution of atherosclerotic lesions, by building up the lesion and taking part in the amplification of the inflammatory response (e.g., production of proinflammatory cytokines and growth factors) [5, 47]. However, macrophages are heterogeneous and it is only recently that the polarization of macrophages has been considered in this context not only in murine models $[22,30]$ but also in human lesions $[48,49]$. The 

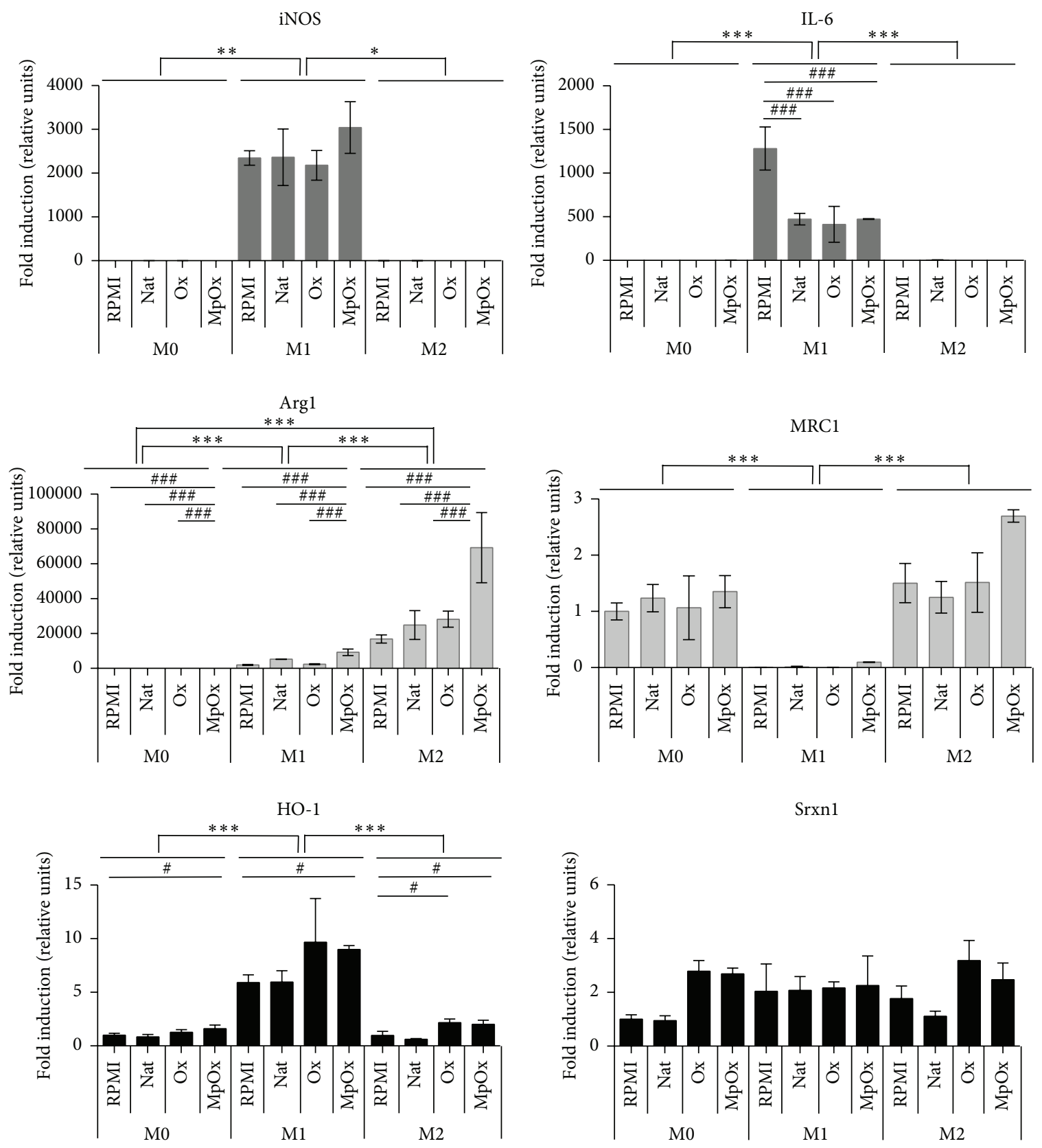

(a)

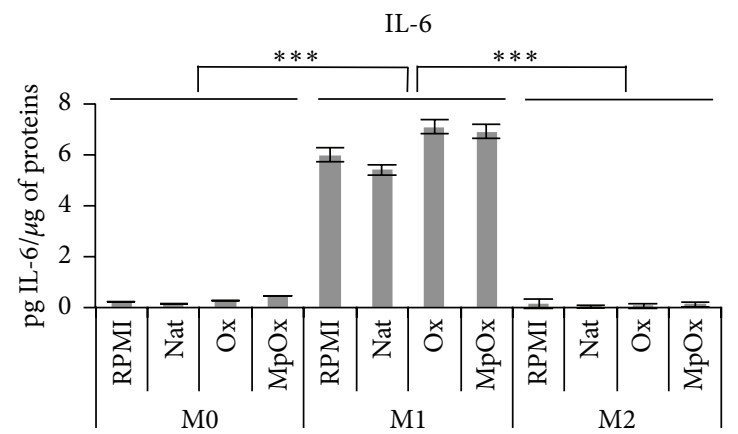

(b1)

Figure 5: Continued. 

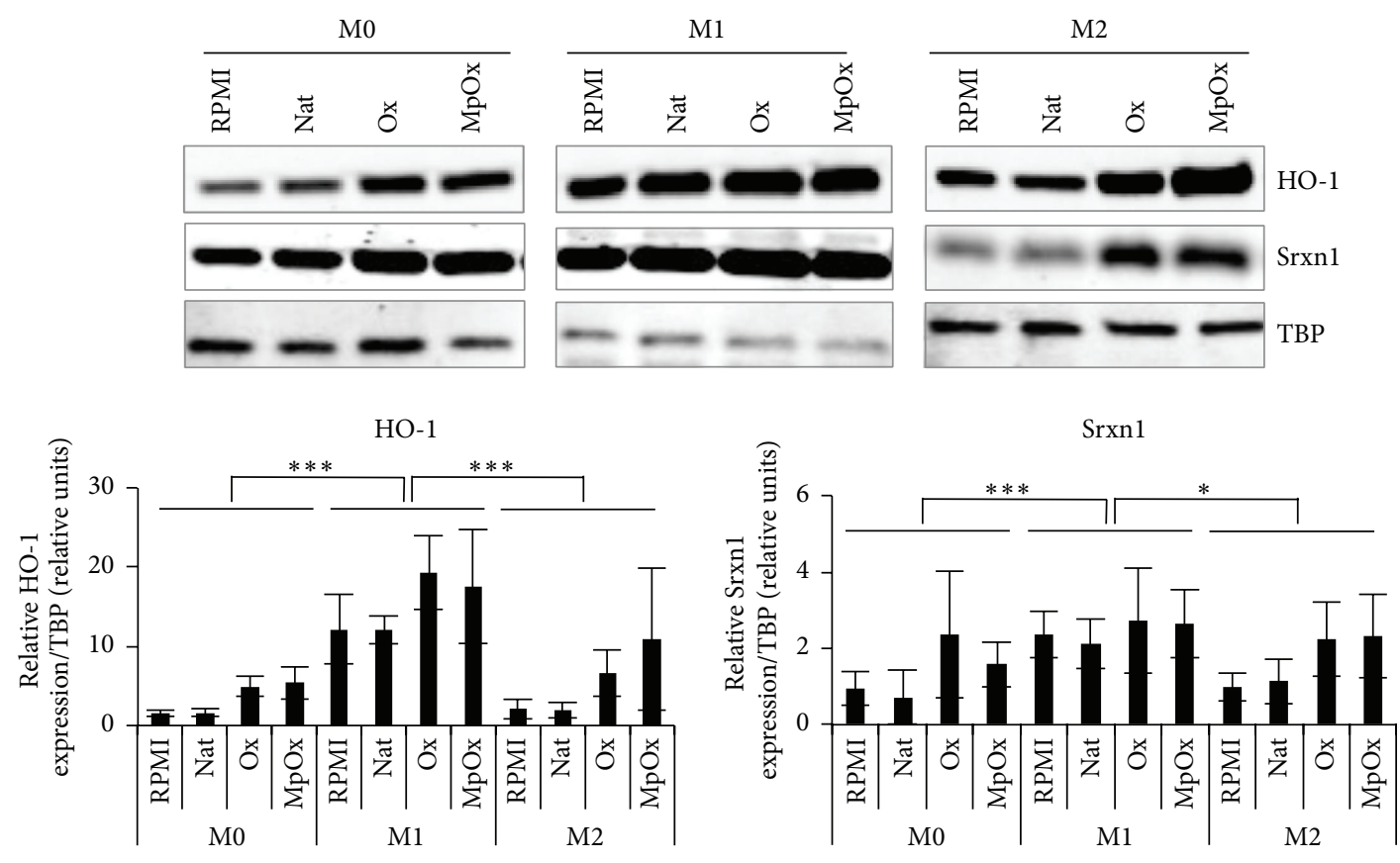

(b2)

(b)

FIGURE 5: Comparative effects of LDLs on (un)polarized BMDMs. M0, M1, and M2 macrophages were stimulated in the presence or absence (RPMI control) of Nat-LDLs, Ox-LDLs, and MpOx-LDLs for 24 hours $(100 \mu \mathrm{g} / \mathrm{mL})$. (a) Expression of polarization marker genes at the mRNA level (RT-qPCR). The expression of marker genes was analyzed by RT-qPCR as described in the preceding figures. Data are normalized with TBP used as housekeeping gene and expressed as mean fold induction relatively to M0 cells in RPMI \pm SD $(n=5)$. Data were analyzed by a Kruskal-Wallis ANOVA on ranks (except for Arg1 and IL-6: two-way ANOVA test). (b) Expression of polarization markers at the protein level (ELISA; WB). (b1) Production of secreted IL-6 (M1 marker) in cell culture supernatants assessed by ELISA. Data are expressed relatively per $\mu \mathrm{g}$ of protein per well as mean $\pm \mathrm{SD}(n=3)$. (b2) Expression of HO-1 and Srxn1 assessed by Western blotting. Data are normalized with TBP used as loading control and expressed as mean $\pm \operatorname{SD}(n=4)$. Results are representative of 4 independent experiments. ANOVA $2:^{*, \#} p<0.05$; ${ }^{* *} p<0.01$; and ${ }^{* * * \# \# \#} p<0.001$."

significance of macrophage polarization in atherogenesis and the identity of the major microenvironmental factors present in the lesion that drive macrophage polarization, as the lesion evolves, remain, however, largely unknown [7, 49-51].

Macrophage polarization has been mainly characterized in vitro using different models. Khallou-Laschet and coworkers obtained polarized macrophages from bone marrowderived cells of 6-to-10-week-old C57BL/6 or ApoE ${ }^{-/-}$mice [30]. Lopez-Castejón et al. polarized peritoneal macrophages isolated from C57BL/6 mice [31, 52]. Human circulating monocytes isolated from healthy human donors and differentiated into macrophages by adding M-CSF to the culture medium were polarized into M1 and M2 cells [32, 53]. Human macrophages differentiated from monocytic THP-1 cells (see, for instance, [54]) or derived from induced pluripotent stem cells have also been polarized [19].

Macrophage activation and polarization are complex phenomena giving rise to confusing descriptors in the literature. Recently, a group of macrophage biologists proposed "Nomenclature and Experimental Guidelines" for a consensus macrophage activation/polarization nomenclature. In this paper, we maintained the classical M1 and M2 nomenclature, considering that it can be translated by M(LPS + IFN- $\gamma$ ) and M(IL-4 + IL-13) macrophages, respectively [26].
In this study, RAW 264.7 cells and BMDMs were polarized into M1 macrophages, after 18 hours of stimulation with LPS and IFN $-\gamma$, while the M2 phenotype was obtained with IL-4 and IL-13, using well-described protocols [22], except for the LPS concentration, which was reduced to $10 \mathrm{ng} / \mathrm{mL}$ to limit cytotoxicity (data not shown). IFN- $\gamma$ alone, compared to the LPS + IFN- $\gamma$ cocktail, was unable to polarize RAW 264.7 cells into M1 cells, with TNF- $\alpha$ being the only M1 marker gene slightly induced, with increased production of secreted TNF$\alpha$, which is in agreement with the data of our group on THP-1 derived macrophages [54].

Polarization was assessed by monitoring the expression of several specific marker genes mainly at the mRNA level and also at the protein level for some markers. iNOS, $I L-6$, Arg2, TNF- $\alpha$, and IL-12 were chosen as proinflammatory M1 markers, Arg1, MRC1, Mgl2, YM1, and IL-10 were chosen as M2 markers, and HO-1 and Srxn1 were chosen as MOX and redox-sensitive markers [30-33], although we are aware that, whatever the model used, M1 and M2 cells represent two extremes of a spectrum of macrophage functions.

Our results in RAW 264.7 macrophages were consistent with data obtained with murine bone marrow-derived macrophages from the study of Khallou-Laschet et al. in 2010 [30] and with BMDMs characterized in this study 

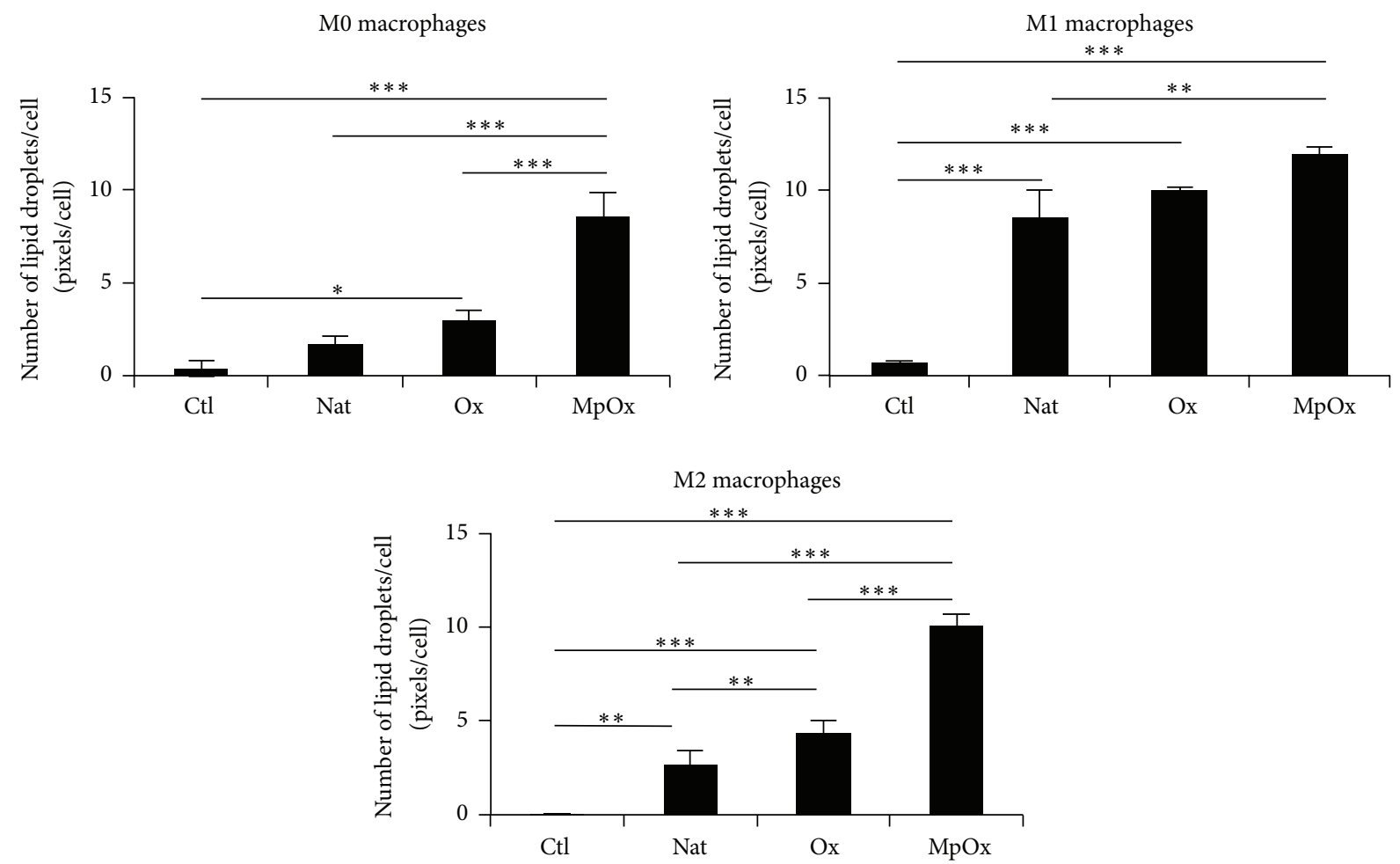

FIGURE 6: Comparative effects of LDLs on (un)polarized RAW 264.7 macrophages to induce foam cells. M0, M1, and M2 macrophages were incubated in the presence or absence of Nat-LDLs, Ox-LDLs, and MpOx-LDLs $(100 \mu \mathrm{g} / \mathrm{mL})$ for 24 hours. The number of lipid droplets was estimated using a High Content Imager, as described in Materials and Methods. Data are expressed as mean \pm SD $(n=3)$. ANOVA 1: ${ }^{*} p<0.05 ;{ }^{* *} p<0.01 ;$ and ${ }^{* * *} p<0.001$

(Figure 2). Indeed, as Khallou-Laschet et al., we observed an overexpression of not only iNOS and IL-6 but also Arg2, TNF$\alpha$, and IL-12 in M1 macrophages. M2 cells overexpressed Arg1 and $M R C 1$ as well as Mgl2, YM1, and IL-10, often considered as canonical M2 markers, at least in mice (for Arg1, $\mathrm{Mgl2}$, and YM1) $[30,55]$.

In addition to avoiding bone marrow or elicited peritoneal macrophage isolation from mice and being useful and convenient in studies related to atherosclerosis, the RAW 264.7 polarized macrophages could also be used in the context of other chronic inflammatory diseases including cancer, particularly to dissect signaling mechanisms or design coculture models.

Once this model of polarized macrophages was validated, we investigated the effects of native LDLs or oxidized LDLs on macrophage polarization, since LDLs play a major role in atherogenesis and in particular oxidized LDLs [56, 57]. The latter accumulating in the lesion could contribute to changes into the macrophage microenvironment modulating their phenotypes and functions. Within the lesion, oxidized LDLs are recognized by scavenger receptors (e.g., CD36, SRA1, and LOX-1), mainly expressed by macrophages, leading to the internalization of modified LDLs. Scavenger receptors, contrary to the native LDL receptors, are not regulated by intracellular cholesterol, contributing to unregulated lipid loading, leading to foam cells $[5,58]$. But how oxidized LDLs interfere with macrophage polarization remains largely unexplored. By the way, most of the available data is focused on copper-oxidized LDLs, oxidized at both the protein and lipid moieties and particularly enriched in lipid hydroperoxides. Hirose et al. (2011) evaluated the effects of OxLDLs on human polarized macrophages, using microarrays, but after 6 hours of incubation, which clearly affects the expression profiles differentially in M0, M1, and M2 cells but remains short for assessing polarizing effects, requiring periods of time of at least 18 hours. It has to be mentioned that only copper-oxidized LDLs were evaluated and gene expression was assessed exclusively at the mRNA level [32]. Isa et al. (2011) also assessed the impact of Ox-LDLs on human polarized macrophages. They determined that M2 macrophages are more sensitive to the lipotoxicity induced by Ox-LDLs, as compared to M0 macrophages and to monocytes. Anew, in the latter study, only copper-oxidized LDLs were evaluated and only M0 and M2 macrophages were taken into account [59]. van Tits et al. (2011) have shown that Ox-LDLs enhance proinflammatory responses stimulated by LPS in human M2 macrophages, which is in agreement with our data showing proinflammatory effects of Ox-LDLs. They hypothesized that this phenotypic switch could play a role in atherogenesis, but, again in this study, only copper-oxidized LDLs were used [51]. However, other oxidized forms of LDLs, probably more relevant, have been described, such as myeloperoxidase-oxidized LDLs $[60,61]$. The latter display specific modifications of Apo-B100 and their lipid hydroperoxide content remains low [36]. Calay et al. already showed that Ox-LDLs and MpOx-LDLs induce 



(a)
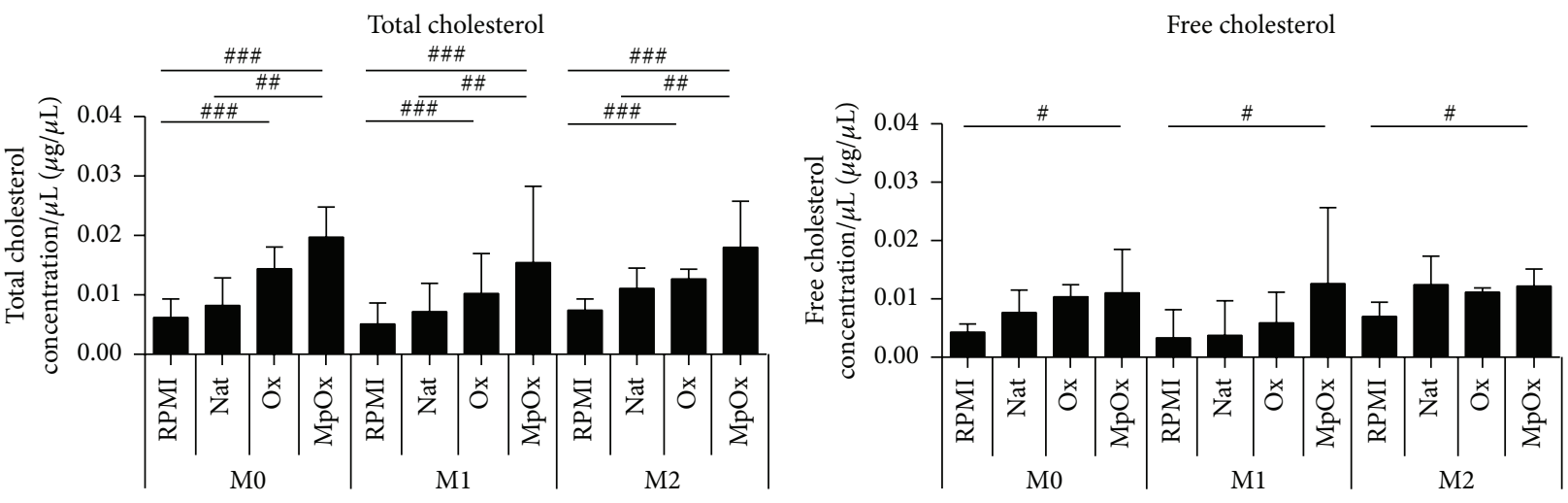

Esterified cholesterol

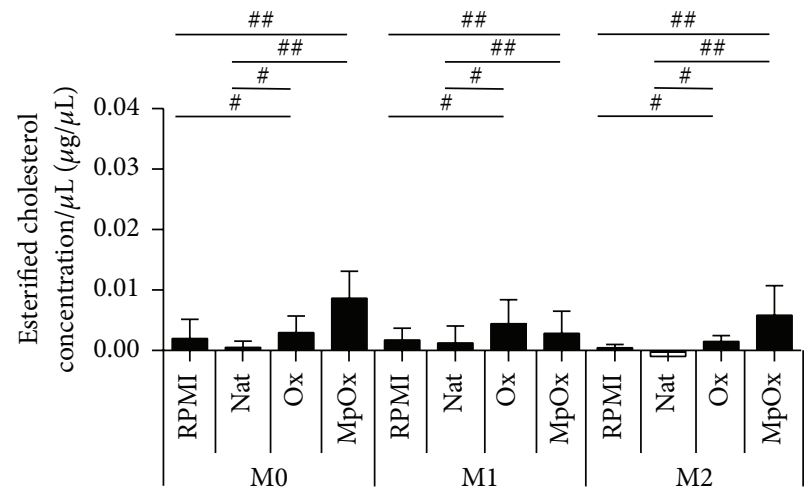

(b)

Figure 7: Comparative effects of LDLs on (un)polarized BMDMs to induce foam cells. (a) M0, M1, and M2 macrophages were incubated in the presence or absence of Nat-LDLs, Ox-LDLs, and MpOx-LDLs $(100 \mu \mathrm{g} / \mathrm{mL})$ for 24 hours. The number of lipid droplets was estimated using a High Content Imager, as described in Materials and Methods. Data are expressed as mean \pm SD $(n=4)$. ANOVA 1: ${ }^{*} p<0.05$ and ${ }^{* * *} p<0.001$. (b) Intracellular cholesterol content in M0, M1, and M2 macrophages incubated in the presence or absence of Nat-LDLs, Ox-LDLs, and MpOx-LDLs for 24 hours. The intracellular cholesterol was measured by a colorimetric assay (absorbance: $570 \mathrm{~nm}$ ). Data are expressed as $\mu \mathrm{g} / \mu \mathrm{L}$ of free, esterified, and total cholesterol (mean $\pm \mathrm{SD}(n=3)$ ). Data were analyzed by a Kruskal-Wallis ANOVA on ranks. ANOVA $1:{ }^{*} p<0.05$ and ${ }^{* *} p<0.01$. 
different responses in RAW 264.7 unpolarized macrophages, with MpOx-LDLs being the most potent in activating Nrf2 and in lipid loading [8]. That is why we wanted to pursue this comparative study on Ox-LDLs and MpOx-LDLs but taking into account the macrophage phenotype.

In this study, we first wondered whether oxidized LDLs could by themselves polarize macrophages, given the paucity of available data. From our data, we can conclude that oxidized LDLs do not lead to a defined polarized phenotype. However, the expression of several marker genes is affected in particular by MpOx-LDLs which favor the expression of not only both redox-sensitive and M2 marker genes but also M1 marker genes. Calay et al. have already shown that MpOx-LDLs more efficiently activate Nrf2, at least in M0 cells, but further studies will be required to unravel more in detail the signaling pathways activated by different kinds of oxidized LDLs in macrophages [8, 62]. Our data suggest that qualitative differences in LDL composition in the atheroma could modulate macrophage polarization and play a role in the evolution of the lesion. Khallou-Laschet and coworkers showed that M2 macrophages were predominant in early atherosclerotic lesions of ApoE KO mice, while M1 macrophages were the predominant phenotype in advanced lesions. It remains unclear whether M2 macrophages are progressively replaced by $\mathrm{M} 1$ cells or whether there is a phenotypic switch [30]. However, data from Davis recently showed that in vitro macrophages could be able to repolarize by themselves in response to changes in the microenvironment (e.g., cytokines) in the context of an infection with Cryptococcus neoformans [63]. It will be worthwhile in the future to confirm the phenotypic distribution of macrophages in atheromas taking into account the M1 and M2 cells in lesions using alternative murine models closer to the human situation.

We then evaluated the effects of LDLs on polarized macrophages, focusing on marker gene expression. Regarding M1 cells, we observe no major effect of LDLs, whether oxidized or not, neither on the expression of iNOS (mRNA) (except for an increased iNOS expression in M1 cells in the presence of MpOx-LDLs) nor on the expression of IL6 (protein). However, in RAW 264.7 M0 cells, MpOx-LDLs, contrary to Ox-LDLs, seemed to induce an overexpression of Arg1, MRC1 (mRNA), and IL-10 (protein) well described as M2 markers and anti-inflammatory genes [64]. In M1 macrophages, Arg1 was significantly overexpressed in the presence of MpOx-LDLs. The M2 phenotype is generally maintained (Nat-LDLs and Ox-LDLs) or even reinforced (MpOx-LDLs) regarding MRC1, Arg1, and YM1 expression and IL-10 secretion, with some variations between RAW 264.7 cells and BMDMs. Interestingly, oxidized LDLs also favor the expression of the protective antioxidant enzymes HO-1 and Srxn1 not only in M1 cells but also in M0 and M2 cells, in particular for MpOx-LDLs in RAW 264.7 cells. When comparing quantitatively RAW 264.7 macrophages and BMDMs, the response in BMDMs was less pronounced. We cannot exclude the fact that BMDMs would have already initiated M2 polarization due to the presence of M-CSF in the macrophage-differentiation conditioned medium.
Polarized macrophages (RAW 264.7 or BMDMs) also showed an important ability to become foam cells when incubated with oxidized LDLs (Figures 6 and 7). Our data suggest that M1 and M2 macrophages have a high potential to engulf lipids, in particular when they are stimulated with MpOx-LDLs. Surprisingly, in addition to taking up oxidized LDLs, M1 macrophages also engulf native LDLs (Figure 6). This phenomenon could be explained by their likely exacerbated oxidative metabolism activated by LPS. As a consequence, this could lead to oxidation of Nat-LDLs during the 24-hour incubation, allowing their intracellular accumulation $[12,15]$. While the cholesterol content increased in BMDMs incubated with LDLs (Figure 7(b)), this could not be demonstrated in RAW 264.7 cells.

Our data show that the number (and size) of lipid droplets is higher in macrophages incubated with $\mathrm{MpOx}-$ LDLs whatever the phenotype in both RAW 264.7 cells and BMDMs. Figure 7(b) shows that, in BMDMs, total cholesterol is also comparable in MpOx-LDLs-treated BMDMs whatever the phenotype. These data suggest that the uptake of $\mathrm{MpOx}-$ LDLs by itself is not sufficient to explain the changes in gene expression. One possible hypothesis that could explain our data (at least in part) could be the presence of different combinations of miRNAs. Polarized macrophages display different miRNA profiles $([65,66]$ both on human monocytederived macrophages). Oxidized LDLs also affect miRNA profiles [62]. But, to our knowledge, there are no data comparing miRNA expression profiles in macrophages taking into account both the macrophage phenotype and different LDL oxidation protocols. But one can imagine that some of the anti-inflammatory and antioxidant effects induced by MpOx-LDLs we observe could be explained by different miRNA combinations resulting from the polarization process and varying according to the type of LDLs used (Nat-LDLs, Ox-LDLs, or MpOx-LDLs).

Altogether these data suggest that MpOx-LDLs are rather anti-inflammatory, in particular by favoring the overexpression of Arg1, and protective, inducing antioxidant enzymes such as HO-1 and Srxn1, while the effects are less clear for Ox-LDLs. Our data are original, since we could not find any study comparing the effects of Ox-LDLs and MpOx-LDLs on polarized macrophages. LDLs, oxidized or not, did not affect the phagocytosis potential whatever the phenotype in both RAW 264.7 cells and BMDMs.

\section{Conclusion}

In conclusion, an easy-to-set up and easy-to-use model of polarized RAW 264.7 has been described and used in this study to better distinguish the effects of copper-oxidized and myeloperoxidase-oxidized LDLs on polarized macrophages. Our data suggest that MpOx-LDLs are the most effective in modulating marker gene expression in unpolarized cells and in inducing an anti-inflammatory and anti-oxidant phenotype compared to Ox-LDLs and finally seem also to be the most efficiently cleaned up by the macrophages whatever their phenotype, which is in agreement with the data of Calay et al. (2010) [8] on murine M0 cells and the data of van Tits 
et al. (2011) on human M1 and M2 cells [51]. Further studies will be needed in order to determine the specific roles of those macrophages in atherosclerosis (genesis, progression, and regression), taking into account different forms of more relevant oxidized LDLs.

\section{Abbreviations}

\begin{tabular}{|c|c|}
\hline Arg1: & Arginase-1 \\
\hline Arg2: & Arginase-2 \\
\hline BMDMs: & $\begin{array}{l}\text { Bone marrow-derived } \\
\text { macrophages }\end{array}$ \\
\hline CD36: & Cluster of differentiation 36 \\
\hline DMPC: & $\begin{array}{l}\text { 1,2-Dimyristoyl-sn-glycero-3- } \\
\text { phosphocholine }\end{array}$ \\
\hline GM-CSF: & $\begin{array}{l}\text { Granulocyte-macrophage } \\
\text { colony-stimulating factor }\end{array}$ \\
\hline HO-1: & Heme oxygenase- 1 \\
\hline IL-4: & Interleukin-4 \\
\hline IL-6: & Interleukin-6 \\
\hline IL-10: & Interleukin-10 \\
\hline IL-12: & Interleukin-12 \\
\hline IL-13: & Interleukin-13 \\
\hline iNOS: & $\begin{array}{l}\text { Inducible Nitric Oxide } \\
\text { Synthase }\end{array}$ \\
\hline LDL-R: & $\begin{array}{l}\text { Low-density lipoprotein } \\
\text { receptor }\end{array}$ \\
\hline LPS: & Lipopolysaccharide \\
\hline M-CSF: & $\begin{array}{l}\text { Macrophage } \\
\text { colony-stimulating factor }\end{array}$ \\
\hline Nat-LDLs: & $\begin{array}{l}\text { Native low-density } \\
\text { lipoproteins }\end{array}$ \\
\hline M1: & $\begin{array}{l}\text { Proinflammatory } \\
\text { macrophages or "classically" } \\
\text { activated macrophages }\end{array}$ \\
\hline M2: & $\begin{array}{l}\text { Anti-inflammatory } \\
\text { macrophages or } \\
\text { "alternatively" activated } \\
\text { macrophages }\end{array}$ \\
\hline MCP-1: & $\begin{array}{l}\text { Monocyte chemoattractant } \\
\text { protein-1 }\end{array}$ \\
\hline Mgl2: & $\begin{array}{l}\text { Macrophage galactose } \\
\mathrm{N} \text {-acetyl-galactosamine } \\
\text { specific lectin } 2\end{array}$ \\
\hline MOX: & $\begin{array}{l}\text { Oxidized } \\
\text { phospholipid-induced } \\
\text { macrophages }\end{array}$ \\
\hline MpOx-LDLs: & $\begin{array}{l}\text { Myeloperoxidase-oxidized } \\
\text { low-density lipoproteins }\end{array}$ \\
\hline MPO: & Myeloperoxidase \\
\hline MRC1: & Mannose receptor type-C1 \\
\hline Nrf2: & $\begin{array}{l}\text { Nuclear factor erythroid } \\
\text { 2-related factor } 2\end{array}$ \\
\hline Ox-LDLs: & $\begin{array}{l}\text { Copper sulfate-oxidized } \\
\text { low-density lipoproteins }\end{array}$ \\
\hline OxPAPC: & $\begin{array}{l}\text { Oxidized 1-palmitoyl-2- } \\
\text { arachidonoyl-sn-glycero-3- } \\
\text { phosphorylcholine }\end{array}$ \\
\hline PFA: & Paraformaldehyde \\
\hline
\end{tabular}

ROS: Reactive oxygen species

RNS: Reactive nitrogen species

SR-A1: Scavenger receptor type A1

Srxn1: Sulfiredoxin-1

TNF- $\alpha$ Tumor necrosis factor- $\alpha$

WHO: World Health Organization

YM1: Beta-N-acetylhexosaminidase, also known as Chil3, chitinase-like protein 3.

\section{Competing Interests}

The authors declare that there are no competing interests regarding the publication of this paper.

\section{Authors' Contributions}

Valérie Pireaux was in charge of the experimental work (with the technical help of Martine Van Steenbrugge) and of the writing of the manuscript. Aude Sauvage supported Valérie Pireaux for the analyses of samples with the high content BD Pathway 855 Imager and for the preparation of oxidized LDLs. Benoît Bihin helped Valérie Pireaux in R programming and in the statistical analyses (two-way ANOVA). Alexandre Rousseau isolated the LDLs. The experimental work was supervised by Martine Raes and Karim Zouaoui Boudjeltia and the writing of the manuscript was supervised by Martine Raes, Karim Zouaoui Boudjeltia, and Pierre Van Antwerpen.

\section{Acknowledgments}

The authors thank Dr. Pierrick Uzureau for his critical proofreading of the manuscript and Dr. Christophe Lelubre for advising on the statistical analyses. This study was in part supported by FSR funding of the University of Namur (UNamur), Belgium, and by FRIA grant and by the FRSFNRS (Brussels, Belgium) (2.5008.11) for the acquisition of the BD Pathway 855 Imager of the Morphologic platform of the UNamur.

\section{References}

[1] P. Aukrust, B. Halvorsen, A. Yndestad et al., "Chemokines and cardiovascular risk," Arteriosclerosis, Thrombosis, and Vascular Biology, vol. 28, no. 11, pp. 1909-1919, 2008.

[2] A. J. Lusis, "Atherosclerosis," Nature, vol. 407, no. 6801, pp. $233-$ 241, 2000.

[3] J. Sanz and Z. A. Fayad, "Imaging of atherosclerotic cardiovascular disease," Nature, vol. 451, no. 7181, pp. 953-957, 2008.

[4] K. J. Woollard and F. Geissmann, "Monocytes in atherosclerosis: subsets and functions," Nature Reviews Cardiology, vol. 7, no. 2, pp. 77-86, 2010.

[5] P. Libby, "Inflammation in atherosclerosis," Nature, vol. 420, no. 6917, pp. 868-874, 2002.

[6] P. Webb, "Alternative macrophage activation and the regulation of metabolism," F1000 Biology Reports, vol. 1, article 2, p. 3, 2009.

[7] I. M. J. Wolfs, M. M. P. C. Donners, and M. P. J. de Winther, "Differentiation factors and cytokines in the atherosclerotic plaque micro-environment as a trigger for macrophage polarisation," Thrombosis and Haemostasis, vol. 106, no. 5, pp. 763-771, 2011. 
[8] D. Calay, A. Rousseau, L. Mattart et al., "Copper and myelop -eroxidase-modified LDLs activate Nrf2 through different pathways of ros production in macrophages," Antioxidants and Redox Signaling, vol. 13, no. 10, pp. 1491-1502, 2010.

[9] C. K. Glass and J. L. Witztum, "Atherosclerosis: the road ahead," Cell, vol. 104, no. 4, pp. 503-516, 2001.

[10] C. J. Pepine, "Why vascular biology matters," American Journal of Cardiology, vol. 88, no. 8, pp. 5K-9K, 2001.

[11] A. Mantovani, A. Sica, and M. Locati, "Macrophage polarization comes of age," Immunity, vol. 23, no. 4, pp. 344-346, 2005.

[12] J. A. Van Ginderachter, K. Movahedi, G. Hassanzadeh Ghassabeh et al., "Classical and alternative activation of mononuclear phagocytes: picking the best of both worlds for tumor promotion," Immunobiology, vol. 211, no. 6-8, pp. 487-501, 2006.

[13] Y.-C. Liu, X.-B. Zou, Y.-F. Chai, and Y.-M. Yao, "Macrophage polarization in inflammatory diseases," International Journal of Biological Sciences, vol. 10, no. 5, pp. 520-529, 2014.

[14] A. Mantovani, A. Sica, S. Sozzani, P. Allavena, A. Vecchi, and M. Locati, "The chemokine system in diverse forms of macrophage activation and polarization," Trends in Immunology, vol. 25, no. 12, pp. 677-686, 2004.

[15] A. Mantovani, A. Sica, and M. Locati, "New vistas on macrophage differentiation and activation," European Journal of Immunology, vol. 37, no. 1, pp. 14-16, 2007.

[16] D. M. Mosser, "The many faces of macrophage activation," Journal of Leukocyte Biology, vol. 73, no. 2, pp. 209-212, 2003.

[17] D. M. Mosser and J. P. Edwards, "Exploring the full spectrum of macrophage activation," Nature Reviews Immunology, vol. 8, no. 12, pp. 958-969, 2008.

[18] A. C. Labonte, A.-C. Tosello-Trampont, and Y. S. Hahn, "The role of macrophage polarization in infectious and inflammatory diseases," Molecules and Cells, vol. 37, no. 4, pp. 275-285, 2014.

[19] K. L. Spiller, E. A. Wrona, S. Romero-Torres et al., "Differential gene expression in human, murine, and cell line-derived macrophages upon polarization," Experimental Cell Research, 2015.

[20] S. K. Biswas, M. Chittezhath, I. N. Shalova, and J.-Y. Lim, "Macrophage polarization and plasticity in health and disease," Immunologic Research, vol. 53, no. 1-3, pp. 11-24, 2012.

[21] G. Chinetti-Gbaguidi and B. Staels, "Macrophage polarization in metabolic disorders: functions and regulation," Current Opinion in Lipidology, vol. 22, no. 5, pp. 365-372, 2011.

[22] A. Kadl, A. K. Meher, P. R. Sharma et al., "Identification of a novel macrophage phenotype that develops in response to atherogenic phospholipids via Nrf2," Circulation Research, vol. 107, no. 6, pp. 737-746, 2010.

[23] S. Adamson and N. Leitinger, "Phenotypic modulation of macrophages in response to plaque lipids," Current Opinion in Lipidology, vol. 22, no. 5, pp. 335-342, 2011.

[24] S. Akiba, Y. Yoneda, S. Ohno, M. Nemoto, and T. Sato, "Oxidized LDL activates phospholipase A2 to supply fatty acids required for cholesterol esterification," Journal of Lipid Research, vol. 44, no. 9, pp. 1676-1685, 2003.

[25] S. B. Joseph, A. Castrillo, B. A. Laffitte, D. J. Mangelsdorf, and P. Tontonoz, "Reciprocal regulation of inflammation and lipid metabolism by liver X receptors," Nature Medicine, vol. 9, no. 2, pp. 213-219, 2003.

[26] P. J. Murray, J. E. Allen, S. K. Biswas et al., "Macrophage activation and polarization: nomenclature and experimental guidelines," Immunity, vol. 41, no. 1, pp. 14-20, 2014.
[27] W. Ying, P. S. Cheruku, F. W. Bazer, S. H. Safe, and B. Zhou, "Investigation of macrophage polarization using bone marrow derived macrophages," Journal of Visualized Experiments, vol. 76, Article ID e50323, 2013.

[28] B. K. Davis, "Evaluation of classical, alternative, and regulatory functions of bone marrow-derived macrophages," Methods in Molecular Biology, vol. 1032, pp. 79-89, 2013.

[29] M. A. P. Oliveira, G. M. A. C. Lima, M. T. Shio, P. J. M. Leenen, and I. A. Abrahamsohn, "Immature macrophages derived from mouse bone marrow produce large amounts of IL-12p40 after LPS stimulation," Journal of Leukocyte Biology, vol. 74, no. 5, pp. 857-867, 2003.

[30] J. Khallou-Laschet, A. Varthaman, G. Fornasa et al., "Macrophage plasticity in experimental atherosclerosis," PLOS ONE, vol. 5, no. 1, Article ID e8852, 2010.

[31] G. Lopez-Castejón, A. Baroja-Mazo, and P. Pelegrín, "Novel macrophage polarization model: from gene expression to identification of new anti-inflammatory molecules," Cellular and Molecular Life Sciences, vol. 68, no. 18, pp. 3095-3107, 2011.

[32] K. Hirose, K. Iwabuchi, K. Shimada et al., "Different responses to oxidized low-density lipoproteins in human polarized macrophages," Lipids in Health and Disease, vol. 10, article 1, pp. 1-18, 2011.

[33] Y. van Kooyk, J. M. Ilarregui, and S. J. van Vliet, "Novel insights into the immunomodulatory role of the dendritic cell and macrophage-expressed C-type lectin MGL," Immunobiology, vol. 220, no. 2, pp. 185-192, 2015.

[34] C. M. Spickett, A. Jerlich, O. M. Panasenko et al., "The reactions of hypochlorous acid, the reactive oxygen species produced by myeloperoxidase, with lipids," Acta Biochimica Polonica, vol. 47, no. 4, pp. 889-899, 2000.

[35] J. W. Heinecke, "Oxidative stress: new approaches to diagnosis and prognosis in atherosclerosis," American Journal of Cardiology, vol. 91, no. 3, pp. 12A-16A, 2003.

[36] K. Z. Boudjeltia, I. Legssyer, P. Van Antwerpen et al., "Triggering of inflammatory response by myeloperoxidase-oxidized LDL," Biochemistry and Cell Biology, vol. 84, no. 5, pp. 805-812, 2006.

[37] M. Jaguin, N. Houlbert, O. Fardel, and V. Lecureur, "Polarization profiles of human M-CSF-generated macrophages and comparison of M1-markers in classically activated macrophages from GM-CSF and M-CSF origin," Cellular Immunology, vol. 281, no. 1, pp. 51-61, 2013.

[38] D. Y. S. Vogel, J. E. Glim, A. W. D. Stavenuiter et al., "Human macrophage polarization in vitro: maturation and activation methods compared," Immunobiology, vol. 219, no. 9, pp. 695703, 2014.

[39] S. A. Rushworth, X.-L. Chen, N. Mackman, R. M. Ogborne, and M. A. O'Connell, "Lipopolysaccharide-induced heme oxygenase-1 expression in human monocytic cells is mediated via Nrf2 and protein kinase C," Journal of Immunology, vol. 175, no. 7, pp. 4408-4415, 2005.

[40] T. Ashino, R. Yamanaka, M. Yamamoto et al., "Negative feedback regulation of lipopolysaccharide-induced inducible nitric oxide synthase gene expression by heme oxygenase-1 induction in macrophages," Molecular Immunology, vol. 45, no. 7, pp. 2106-2115, 2008.

[41] A.-M. Kuhn, N. Tzieply, M. V. Schmidt et al., "Antioxidant signaling via $\mathrm{Nrf} 2$ counteracts lipopolysaccharide-mediated inflammatory responses in foam cell macrophages," Free Radical Biology and Medicine, vol. 50, no. 10, pp. 1382-1391, 2011.

[42] M. Guilliams, P. Bruhns, Y. Saeys, H. Hammad, and B. N. Lambrecht, "The function of Fc $\gamma$ receptors in dendritic cells and 
macrophages," Nature Reviews Immunology, vol. 14, no. 2, pp. 94-108, 2014.

[43] L. Lefèvre, G. Lugo-Villarino, E. Meunier et al., "The Ctype lectin receptors dectin-1, MR, and SIGNR3 contribute both positively and negatively to the macrophage response to Leishmania infantum," Immunity, vol. 38, no. 5, pp. 1038-1049, 2013.

[44] M. M. Al Gadban, K. J. Smith, F. Soodavar et al., "Differential trafficking of oxidized LDL and oxidized LDL immune complexes in macrophages: impact on oxidative stress," PLoS ONE, vol. 5, no. 9, Article ID e12534, pp. 1-10, 2010.

[45] Y. Xu, J. Wang, Y. Bao et al., "Identification of two antagonists of the scavenger receptor CD36 using a high-throughput screening model," Analytical Biochemistry, vol. 400, no. 2, pp. 207-212, 2010.

[46] K.-J. Min, H. J. Um, K.-H. Cho, and T. K. Kwon, "Curcumin inhibits oxLDL-induced CD36 expression and foam cell formation through the inhibition of p38 MAPK phosphorylation," Food and Chemical Toxicology, vol. 58, pp. 77-85, 2013.

[47] I. M. Fenyo and A. V. Gafencu, "The involvement of the monocytes/macrophages in chronic inflammation associated with atherosclerosis," Immunobiology, vol. 218, no. 11, pp. 13761384, 2013.

[48] M. A. Bouhlel, B. Derudas, E. Rigamonti et al., "PPAR $\gamma$ activation primes human monocytes into alternative M2 macrophages with anti-inflammatory properties," Cell Metabolism, vol. 6, no. 2, pp. 137-143, 2007.

[49] N. Leitinger and I. G. Schulman, "Phenotypic polarization of macrophages in atherosclerosis," Arteriosclerosis, Thrombosis, and Vascular Biology, vol. 33, no. 6, pp. 1120-1126, 2013.

[50] C. Marathe, M. N. Bradley, C. Hong et al., "The arginase II gene is an anti-inflammatory target of liver $\mathrm{X}$ receptor in macrophages," Journal of Biological Chemistry, vol. 281, no. 43, pp. 32197-32206, 2006.

[51] L. J. H. van Tits, R. Stienstra, P. L. van Lent, M. G. Netea, L. A. B. Joosten, and A. F. H. Stalenhoef, "Oxidized LDL enhances pro-inflammatory responses of alternatively activated M2 macrophages: a crucial role for Krüppel-like factor 2," Atherosclerosis, vol. 214, no. 2, pp. 345-349, 2011.

[52] P. Pelegrin, C. Barroso-Gutierrez, and A. Surprenant, "P2X7 receptor differentially couples to distinct release pathways for IL-1 $\beta$ in mouse macrophage," Journal of Immunology, vol. 180, no. 11, pp. 7147-7157, 2008.

[53] F. O. Martinez, S. Gordon, M. Locati, and A. Mantovani, “Transcriptional profiling of the human monocyte-to-macrophage differentiation and polarization: new molecules and patterns of gene expression," The Journal of Immunology, vol. 177, no. 10, pp. 7303-7311, 2006.

[54] M. Genin, F. Clement, A. Fattaccioli, M. Raes, and C. Michiels, "M1 and M2 macrophages derived from THP-1 cells differentially modulate the response of cancer cells to etoposide," $B M C$ Cancer, vol. 15, no. 1, article 577, 2015.

[55] G. Raes, R. Van Den Bergh, P. De Baetselier et al., "Arginase-1 and $\mathrm{Yml}$ are markers for murine, but not human, alternatively activated myeloid cells," Journal of Immunology, vol. 174, no. 11, pp. 6561-6562, 2005.

[56] X.-H. Yu, Y.-C. Fu, D.-W. Zhang, K. Yin, and C.-K. Tang, "Foam cells in atherosclerosis," Clinica Chimica Acta, vol. 424, pp. 245252, 2013.

[57] A. Pirillo, G. D. Norata, and A. L. Catapano, "LOX-1, OxLDL, and atherosclerosis," Mediators of Inflammation, vol. 2013, Article ID 152786, 12 pages, 2013.
[58] J. Canton, D. Neculai, and S. Grinstein, "Scavenger receptors in homeostasis and immunity," Nature Reviews Immunology, vol. 13, no. 9, pp. 621-634, 2013.

[59] S. A. Isa, J. S. Ruffino, M. Ahluwalia, A. W. Thomas, K. Morris, and R. Webb, "M2 macrophages exhibit higher sensitivity to oxLDL-induced lipotoxicity than other monocyte/macrophage subtypes," Lipids in Health and Disease, vol. 10, article 229, 2011.

[60] D. Lau and S. Baldus, "Myeloperoxidase and its contributory role in inflammatory vascular disease," Pharmacology and Therapeutics, vol. 111, no. 1, pp. 16-26, 2006.

[61] N. Moguilevsky, K. Zouaoui Boudjeltia, S. Babar et al., "Monoclonal antibodies against LDL progressively oxidized by myeloperoxidase react with ApoB-100 protein moiety and human atherosclerotic lesions," Biochemical and Biophysical Research Communications, vol. 323, no. 4, pp. 1223-1228, 2004.

[62] E. Zhang and Y. Wu, "MicroRNAs: important modulators of oxLDL-mediated signaling in atherosclerosis," Journal of Atherosclerosis and Thrombosis, vol. 20, no. 3, pp. 215-227, 2013.

[63] M. J. Davis, T. M. Tsang, Y. Qiu et al., "Macrophage $\mathrm{M} 1 / \mathrm{M} 2$ polarization dynamically adapts to changes in cytokine microenvironments in Cryptococcus neoformans infection," mBio, vol. 4, no. 3, Article ID e00264-13, 2013.

[64] J. T. Pesce, T. R. Ramalingam, M. M. Mentink-Kane et al., "Arginase-1-expressing macrophages suppress Th2 cytokinedriven inflammation and fibrosis," PLoS Pathogens, vol. 5, no. 4, Article ID e1000371, 2009.

[65] V. Cobos Jiménez, E. J. Bradley, A. M. Willemsen, A. H. C. van Kampen, F. Baas, and N. A. Kootstra, "Next-generation sequencing of microRNAs uncovers expression signatures in polarized macrophages," Physiological Genomics, vol. 46, no. 3, pp. 91-103, 2014.

[66] J. W. Graff, A. M. Dickson, G. Clay, A. P. McCaffrey, and M. E. Wilson, "Identifying functional microRNAs in macrophages with polarized phenotypes," The Journal of Biological Chemistry, vol. 287, no. 26, pp. 21816-21825, 2012. 


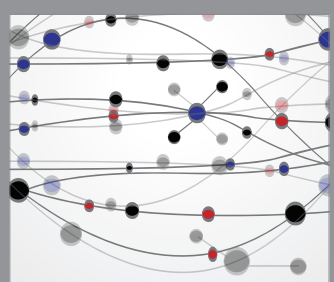

The Scientific World Journal
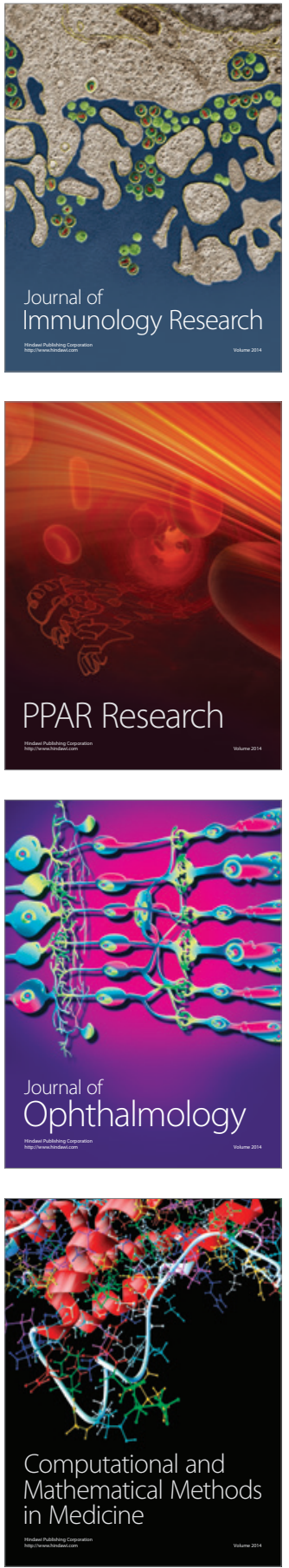

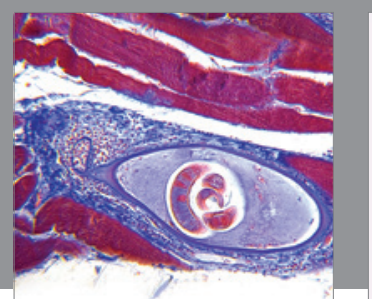

Gastroenterology Research and Practice

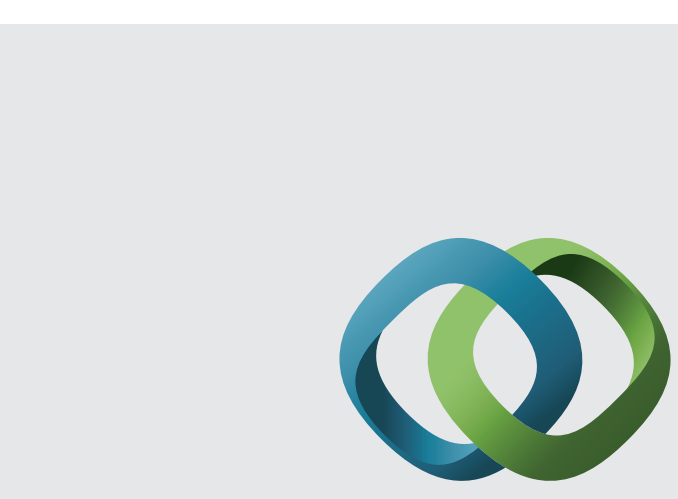

\section{Hindawi}

Submit your manuscripts at

http://www.hindawi.com
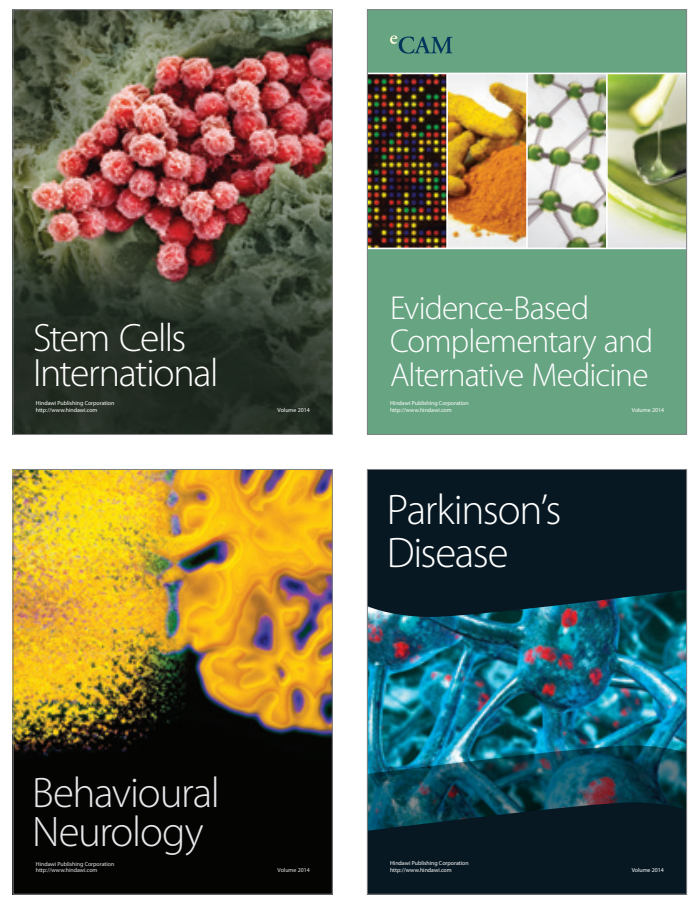
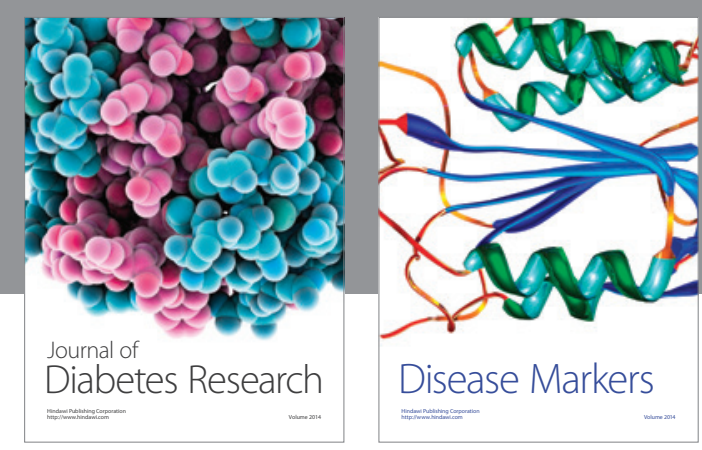

Disease Markers
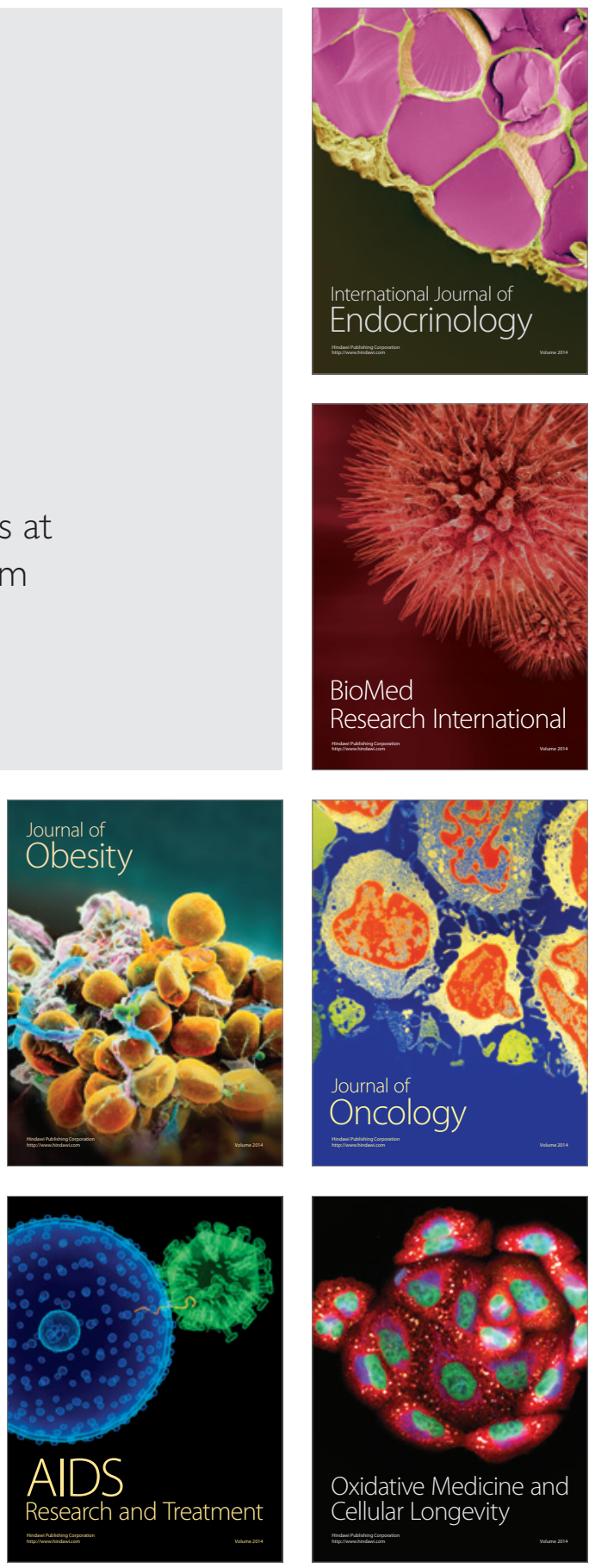